\title{
Tabularia
}

Sources écrites des mondes normands médiévaux Les cartulaires normands. Bilan et perspectives de recherche | 2012

\section{Une « machina memorialis ». Les cartulaires des léproseries de la province ecclésiastique de Rouen}

A "machina memorialis". Cartularies of Leper-Houses in the Ecclesiastical Province of Rouen

Damien Jeanne

(2) OpenEdition

Journals

Édition électronique

URL : http://journals.openedition.org/tabularia/523

DOI : $10.4000 /$ tabularia. 523

ISSN : 1630-7364

Éditeur :

CRAHAM - Centre Michel de Boüard, Presses universitaires de Caen

Référence électronique

Damien Jeanne, «Une «machina memorialis ». Les cartulaires des léproseries de la province

ecclésiastique de Rouen », Tabularia [En ligne], Les cartulaires normands. Bilan et perspectives de recherche, mis en ligne le 06 novembre 2012, consulté le 19 avril 2019. URL : http://

journals.openedition.org/tabularia/523; DOI : 10.4000/tabularia.523 


\title{
Une «machina memorialis». Les cartulaires des léproseries de la province ecclésiastique de Rouen
}

\author{
$A$ «machina memorialis». \\ Cartularies of Leper-Houses \\ in the Ecclesiastical Province of Rouen
}

Damien JEANNE

CRAHAM, UMR 6273 UCBN/CNRS

damien.jeanne@unicaen.fr

Résumé:

Les cartulaires de léproseries sont des manuscrits rares qui sont restés inédits en Normandie. Pourtant, la province ecclésiastique de Rouen dispose à elle seule du tiers des chartriers de léproseries conservés en France au nord de la Loire. Rédigés pour la plupart lors de l'occupation anglaise, les cartulaires sont le produit des inquiétudes d'institutions charitables sur le déclin. Forts de 2004 actes répartis entre les $\mathrm{XII}^{\mathrm{e}}$ et le $\mathrm{XV}^{\mathrm{e}}$ siècles, deux des sept cartulaires de léproseries normandes ont fait l'objet d'éditions non publiées, les autres sont en préparation.

Mots-clés: cartulaire, léproserie, lèpre, mémoire.

\begin{abstract}
:
The cartularies of the Norman leper-houses are rare manuscripts, unpublished so far. Yet, the ecclesiastical province of Rouen can boast a third of the leper-house cartularies preserved in Northern France. Most of them were written during the Lancastrian rule of Normandy. The drawing up of those cartularies resulted from the declining charitable institutions concerns over their future. As many as 2004 acts, ranging from the $12^{\text {th }}$ and the $15^{\text {th }}$ century, contained in two of the seven Norman leper-house cartularies have been edited, but are still unpublished; the rest are under preparation.
\end{abstract}

Keywords: cartulary, leper-house, lepra, memory.

Les cartulaires des léproseries de la province ecclésiastique de Rouen se placent au premier rang des sources pour comprendre le fonctionnement et les évolutions de ces établissements charitables. Qu'est ce qu'un cartulaire? On considère comme cartulaire «toute transcription organisée (sélective ou exhaustive) de documents diplomatiques, réalisée par le détenteur de ceux-ci ou pour son compte, afin d'en assurer la conservation et d'en faciliter la consultation. On le distingue du recueil 
de chartes, établi par un érudit, ancien ou moderne, et non pas par l'intéressé lui-même à l'aide de ses propres documents ${ }^{1}$ ».

En 1991, François-Olivier Touati livrait un premier recensement des cartulaires des léproseries de la France du Nord ${ }^{2}$. La liste dressée à cette occasion doit être augmentée de deux autres cartulaires (Saint-Lazare de Falaise et Notre-Dame de Beaulieu à Caen), voire trois avec un cartulaire perdu de Saint-Nicolas de Bayeux ${ }^{3}$. Notons l'existence d'un cartulaire moderne rédigé autour de 1613 pour la léproserie de Bellême ${ }^{4}$. Enfin, la réalité du «cartulaire» de la léproserie de Breteuil-sur-Iton ${ }^{5}$ reste pour le moins hypothétique ${ }^{6}$. Au total, la province ecclésiastique de Rouen dispose du tiers des cartulaires de la France du Nord (soit 7 cartulaires sur 22). Ramenée à l'ensemble de la production des cartulaires normands, la proportion de ceux écrits pour les maladreries totalise $3 \%$.

C'est en Normandie occidentale et centrale - qui se compose de cinq diocèses (Avranches, Bayeux, Coutances, Lisieux et Sées) - que se trouve la majorité des cartulaires: on en compte six sur une centaine de léproseries attestées avant $135 \mathrm{O}^{7}$ (fig. 1). Tandis que la Normandie orientale (diocèses de Rouen et d'Évreux) n'en conserve qu'un seul, celui de Saint-Nicolas d'Évreux. Hormis le cartulaire de Sainte-Marie-Madeleine de Bolleville ${ }^{8}$, seules les institutions urbaines (Caen, Bayeux, Évreux, Falaise et Pont-Audemer) sont dotées de tels outils. Il n'empêche que certaines grandes léproseries comme celle du Mont-aux-Malades à Rouen n'en gardent nulle trace. Faut-il invoquer les hasards de la conservation? Il est vrai que si l'ancien maire de Bayeux, Antoine-Marc Génas Duhomme (1757-1845), n'avait pas fait don du cartulaire de Saint-Nicolas à la nouvelle bibliothèque municipale le 10 août 1835 , il serait resté dans l'ombre d'une collection privée'. Il le sauve des «six énormes charretées de manuscrits et d'anciens titres» livrées aux flammes le 25 septembre 1793 par la municipalité ${ }^{10}$. Les manuscrits de Notre-Dame

1. Guyotjeannin, Picke et Tock, 1993, p. 277.

2. Ces sources constituent $0,4 \%$ de l'ensemble des cartulaires de même type recensés en France (Touati, 1993, p. 469.)

3. Caen, Arch. dép. Calvados, $\mathrm{H}$ non coté 292, cartulaire de Notre-Dame de Beaulieu [puis cart. Hnc 292] et 386 E dépôt 635, cartulaire de Saint-Lazare [puis cart. Saint-Lazare].

4. Alençon, Arch. dép. Orne, $3 \mathrm{H}$ dépôt B 37. Il comprend 479 pages dont 367 sont écrites; dim. 310 x $200 \mathrm{~mm}$. Les 99 actes couvrent les années 1400 à 1613. La majorité des chartes date du XVI e siècle. Merci à Matthieu Le Goïc pour m'avoir fait connaitre ce document.

5. Dép. Eure, chef-lieu de cant.

6. Il est signalé par A. Le Prévost sans qu'il ne l'ait consulté (Le PrÉvost, 1862, p. 433). Aucun autre auteur ne mentionne cette source (TouATI, 1993, p. 467, n. 2). B. Tabuteau n'a pas trouvé la trace d'un cartulaire médiéval dans le fonds de l'hospice de Breteuil dont les archives n'ont pas été versées dans un dépôt public.

7. JeAnNe, 2010a, t. 2, p. 324-327.

8. Dép. Manche, arr. Coutances, cant. La Haye-du-Puits; Delisle, 1892, p. 16-27.

9. Bayeux, Arch. mun., B 3, cartulaire des délibérations du Conseil municipal (10 août 183531 août 1837), fol. 10, nº 14 (10 août 1835).

10. «L'un des premiers actes du nouveau Conseil général, dont la mission semblait plutôt destructive que conservatrice, fut de livrer aux flammes six énormes charretées de manuscrits et anciens titres, pour la plupart sur parchemins, documents précieux dont l'incinération fut désastreuse pour l'histoire du pays.» (DÉdouit, 1892, p. 42; GARNIER, 1908, p. 8). 
de Beaulieu à Caen sont rescapés des bombardements des 6-7 juin et du 7 juillet 1944; celui de Saint-Lazare de Falaise a échappé aux ravages de la bataille pour la prise de la ville du 14 au 16 août 1944. Le recensement actuel ne se prétend donc qu'estimatif. Il convient de souligner en outre la disparité des lieux de rédaction: le diocèse d'Avranches n'a pas de cartulaire de léproserie attesté. Le cartulaire de Bolleville au diocèse de Coutances a été vendu à la British Library le 12 février 1848 par Charles Duhérissier de Gerville parce qu'il avait besoin d'argent pour acheter des livres!

Ces recueils témoignent de l'importance du patrimoine de ces institutions et leur élaboration répond à des besoins précis. Les cartulaires de la province de Rouen n'ont pas été édités, ni étudiés de manière systématique. Les 2004 actes des cartulaires marquent l'identité des fraternités lépreuses. Les scribes ont retranscrit tout ce qui constitue les léproseries: leurs privilèges, les donations, les baux, les ventes, les contentieux et la disparition de leur autonomie.

Comme le rappelle Pierre Chastang, la pratique de l'écrit révèle des conduites sociales ${ }^{11}$. Dans un temps où l'honneur constitue une des clés des relations humaines, la fonction des cartulaires n'est pas seulement la gestion d'un patrimoine, elle est l'expression de la domination d'une seigneurie collective particulière: une communauté lépreuse conduite par un prieur ou un administrateur. La rédaction de la majorité des cartulaires normands coïncide avec le moment où les lépreux sont devenus minoritaires au sein des léproseries et remplacés par des valides. Si l'identité originelle des fraternités lépreuses tend à s'étioler, comment comprendre la constitution de ces cartulaires? Existe-t-il des points communs ou des différences dans l'objectif des commanditaires? Par qui ont-ils été rédigés? Afin de comprendre leur raison d'être, il convient de se poser la question de l'environnement historique de leur rédaction, de leur rôle comme marqueur d'une identité plurielle et d'analyser les formes et les contenus.

\section{L'environnement historique: des cartulaires «de catastrophe»?}

\section{Les temps des premières inquiétudes: les XIII ${ }^{e}$ et XIV $V^{e}$ siècles}

Le plus ancien cartulaire conservé est celui de Saint-Gilles de Pont-Audemer ${ }^{12}$ dont la rédaction initiale se situe entre 1214-1215 et 1231 et marque l'autonomie institutionnelle de l'établissement. Seul cartulaire de léproserie normande à cette période, le cartulaire de Saint-Gilles est écrit par une douzaine de mains à partir de 1214-1219 jusqu'en $1251^{13}$.

Le caractère composite de ce cartulaire est le reflet des incertitudes consécutives à la commise, puisque cette léproserie dispose de biens en Angleterre concédés par

11. Chastang, 2009, p. 31 et p. 36 .

12. Dép. Eure, chef-lieu de cant.

13. Rouen, Bibl. mun., Y 200, cartulaire de Saint-Gilles de Pont-Audemer, puis cart. Saint-Gilles; Mesmin mac Dougall, 1978, III, p. 169-171; Touati, 1993, p. 473-474 et p. 487-488. 
la famille de Meulan, principale donatrice des lépreux ${ }^{14}$. Le $1^{\text {er }}$ mai 1204, Robert II de Meulan transmet les droits sur ses possessions anglaises à sa fille Mabire. Il cède au roi d'Angleterre tous ses biens de Normandie, mais il en est dépossédé par Philippe Auguste ${ }^{15}$. Les premières chartes (fol. 6-53v) datées du priorat de Thomas entre 1214 et 1231, marquent le désir d'autonomie de la léproserie, au moment où la tutelle seigneuriale s'efface devant l'emprise naissante de la commune de PontAudemer: les bourgeois apparaissent comme garants des donations à partir de $1218^{16}$. Le cartulaire agit comme la mémoire vive de Saint-Gilles ${ }^{17}$ : les sept premiers actes qui ouvrent le cartulaire accordent protection aux lépreux de Saint-Gilles et à leurs biens. Ils se composent de bulles des papes Innocent II, Eugène III et Alexandre III, des donations des comtes de Meulan, des confirmations d'Henri II et de l'archevêque de Rouen Hugues d'Amiens ${ }^{18}$. La rédaction du cartulaire de Saint-Gilles de Pont-Audemer témoigne d'une institution en difficulté relative ${ }^{19}$. Le devenir politique de la famille des principaux donateurs est incertain et la gestion du patrimoine situé outre Manche devient problématique. Le cartulaire révèle aussi l'extension maximale du patrimoine de Saint-Gilles qu'il faut protéger.

C'est seulement à partir de 1215 que les copies - quand elles ne sont pas abrégées - mentionnent les sceaux ${ }^{20}$. Sous l'impulsion des juristes, on s'appuie désormais sur les us et coutumes de Normandie afin de garantir les biens ${ }^{21}$. À partir de 1219, le vocabulaire emprunte aux liens d'homme à homme ${ }^{22}$. Feodo (concéder en fief, fieffer) devient le terme utilisé à partir des années 1220. La réalisation du cartulaire de Pont-Audemer correspond à l'«avènement du style savant ${ }^{23}$ » en essor depuis les injonctions du canon 38 du concile de Latran IV qui considère l'écrit comme une preuve. Le cartulaire révèle ce phénomène en retranscrivant les canons du concile de Latran ${ }^{24}$, des articles sur la nature juridique des biens et les procédures à suivre. Il impose, par la copie des actes, un rapport mémoriel de l'oral à l'écrit.

Le cartulaire de Saint-Nicolas d'Évreux est rédigé à partir de 1239 et l'achèvement de l'ouvrage survient entre 1255 et 1263 . Sa rédaction correspond à un tournant de la vie du patrimoine de l'établissement. Les années 1230-1240

14. Touati, 1993, p. 487-488; JeAnne, 2010a, t. 2, p. 388.

15. Houth, 1981, p. 97-101, no 131, p. 133 et $n^{\circ} 134$, p. 134.

16. Nous suivons François-Olivier Touati sur ce point (TouATI, 1993, p. 488), contrairement à l'interprétation de Simone C. Mesmin Mac Dougall, 1987, p. 242. Cart. Saint-Gilles, fol. 25v, $n^{\circ} 73$.

17. GeARY, 1993, p. 16.

18. Cart. Saint-Gilles, fol. $6, \mathrm{n}^{\circ} 1$; fol. $7, \mathrm{n}^{\circ} 2$; fol. $7, \mathrm{n}^{\circ} 3$; fol. $8, \mathrm{n}^{\circ} 4$; fol. $9, \mathrm{n}^{\circ} 5$; fol. $9 \mathrm{v}, \mathrm{n}^{\circ} 6$; fol. 1ov, $\mathrm{n}^{\circ} 7$.

19. Les cartulaires sont un produit de l'insécurité (ClAnChy, 1983, p. 101).

20. Les chartes sous sceaux privés se développent dans les années 1210 (YvER, 1926, p. 232-233).

21. «... Hanc vero supradictam terram predicti fratres tenentur illi et heredibus suis ad usus et consuetudines Normannie garantizare... », cart. Saint-Gilles, fol. 5ov, nº 130 (1218).

22. «... Ego Thomas prior Sancti Egidii de Ponte Audomari et fratres ejusdem loci tam sani quam infirmi, tradidimus et in feodo concessimus..." cart. Saint-Gilles, fol. 92, n 160 (1219).

23. BARTHÉLEMY, 1993, p. 73 et suiv.

24. Foreville, 1965 , p. 302 et p. 365-366. 
semblent marquer l'apogée des donations et leur déclin. Forte de cette richesse, la léproserie attise toutes sortes de convoitises. Les temps deviennent plus difficiles. Dès 1217-1218, les premiers procès apparaissent. Puis les coutumes de pain et les droits de foires sont contestés ${ }^{25}$. Pour garantir la pérennité des acquêts et l'autonomie de la léproserie ${ }^{26}$, sont couchés par écrit les droits, les protections accordées par les rois et les prélats, toutes les donations et les procès gagnés.

Quelques chartes du cartulaire de Saint-Nicolas de Bayeux réalisé à partir de 1438 signalent l'existence d'un cartulaire plus ancien qui aurait pu être rédigé autour de 1230-1250 (fig. 2). Le nombre des actes qu'il renferme est inconnu. Seules une vente et deux donations nous sont explicitement parvenues ${ }^{27}$. D'autre part, on observe un nombre important de chartes dans les années 1270-1290 dans le cartulaire de 1438. Cette «inflation» documentaire coïncide avec un retournement de conjoncture (les pluies torrentielles qui dévastent les récoltes produisent des disettes; la famine survient à Caen en 1298) ${ }^{28}$. Les entrées des «donnés ${ }^{29}$ » à SaintNicolas se font plus nombreuses, on se met à l'abri des calamités. Pour pallier le manque de numéraire, les droits des léproseries sont battus en brèche et le nombre de procès explose avec les années $1300 / 1320^{30}$. La rédaction d'un "premier " cartulaire pour Saint-Nicolas au début du XIVe siècle en est peut-être la conséquence.

\section{"Âge de plomb, temps pervers, ciel d'airain ${ }^{31} "$}

Trois cartulaires sont composés en 1433, 1436, 1438 et un peut-être vers 1460-1470. Le seul qui date de la reconstruction de la Normandie après le «recouvrement» est celui de Saint-Lazare de Falaise (1487).

La rédaction de ces cartulaires s'inscrit dans une période particulièrement difficile. La compréhension du contexte nécessite de remonter à la conquête de la Normandie par le roi d'Angleterre. Henri V Lancastre (1413-1422) revendique le royaume de France depuis 1414. Le roi chevauche en Normandie à partir du $1^{\text {er }}$ août 1415 avec une armée de 10000 à 12000 hommes et prend Harfleur le 28 septembre 1415, prélude à la conquête de la province. L'armée française est vaincue à Azincourt le 24 octobre 1415. L'invasion de la Normandie est préparée

25. Tabuteau, 1996, 1 B, p. 245 et suiv.

26. Touati, 1993 , p. 480 .

27. "Collacion faicte a l'ancien chartrier dudit prioure», Bayeux, Bibl. mun., ms 1 du cartulaire de Saint-Nicolas, p. 42-44, $\mathrm{n}^{\circ} 56, \mathrm{n}^{\circ} 57, \mathrm{n}^{\circ} 58$ (1332-1348), puis cart. Saint-Nicolas.

28. Bois, 1981, p. 239-245; CASSARd, 2011, p. 563-572; JeAnNe, 2010a, t. 2, p. 468; TAButeau, 1996, 1 B, p. 242-243.

29. Retraite religieuse pour un ou une laïque dans un monastère, un hôtel-Dieu ou une léproserie qui équivaut au sacrifice non sanglant de soi, à l'imitation de la donation du Christ aux hommes (Miramon, 1999, p. 56). Cela revient à appliquer cette sentence de saint Paul: «Je vous exhorte donc, frères, au nom de la miséricorde de Dieu, à vous offrir vous-mêmes en sacrifice vivant, saint et agréable à Dieu.» Rm, 12,1.

30. JEANNE, 2010a, t. 2, p. 543.

31. Deschamps, 1878, p. 292 (1394) cité par J.-L. Biget dans Bove, 2010, p. 5. 
au printemps 1417. La flotte française est détruite le 29 juin. Le $1^{\mathrm{er}}$ août, Henri V peut débarquer en Normandie. Caen capitule le 19 septembre 1417 . Rouen se rend le 13 janvier 1419. Au 9 décembre 1419, toute la Normandie, sauf le Mont Saint-Michel, est sous domination anglaise. Le bourgeois de Paris dresse un saisissant portrait de la guerre:

Hélas tout premier Normandie en est toute exilée, et la plus grande partie qui soulait faire labourer et être en son [lieu], lui, sa femme, sa mesnie, et être sans danger, marchand, marchandises, gens d'église, moines, nonnains, gens de tous états, ont été boutés hors de leur lieux, étrangers comme si eussent été bêtes sauvages [...] Hélas! tant d'enfants morts [nés] par faute d'aide, tant de morts sans confession, par tyrannie et en autre manière, tant de morts sans sépulture en forêts et en autre destour, tant de mariages qui ont été délaissés à faire, tant d'églises arses et brûlées, et chapelles, maisons Dieu, maladeries où on soulait faire le saint service Notre Seigneur et les œuvres de miséricorde ${ }^{32} \ldots$

Pendant trente-trois ans, la Normandie est tenue par les Lancastre. Le traité de Troyes du 21 mai 1420 mentionne qu'à la mort d'Henri $\mathrm{V}$, son héritier doit porter le titre de roi de France (art. 6). Aussitôt, le nouveau maître anglais promeut une politique de concorde ${ }^{33}$ en confirmant chartes et privilèges ${ }^{34}$. Il tente d'unifier la monnaie, les poids et mesures pour rassurer les marchands ${ }^{35}$. Pour séduire la population, le roi se présente en libérateur en promulguant le 4 mai 1418 une ordonnance selon laquelle la taxe sur le sel est réduite de 50 à $25 \%^{36}$. Il punit les razzias des soldats ${ }^{37}$ et les «brigands ${ }^{38}$ » qui se rebellent, et remet les droits spoliés aux mains de leurs légitimes propriétaires, si ceux-ci ne se sont pas compromis avec «l'ennemi». À Bayeux, Saint-Nicolas fait l'objet, dès décembre (?) 1417, d'une protection particulière du roi ${ }^{39}$ et voit la jouissance de son temporel confirmée le

32. Beaune, Journal..., p. 151-152. Parmi les témoignages de Normands qui corroborent le bourgeois, notons celui de Thomas Basin: «Caen fut pillé, beaucoup de bourgeois furent massacrés et spoliés de leurs biens. Après ce désastre, la peur se répandant de plus en plus, les Anglais n'eurent aucune peine à s'emparer de plusieurs places et bourgs de la basse Normandie.» SAMARAN, Histoire..., p. 53.

33. Newhall, 1929, p. 205-229; Mollat, 1952, p. 27-31 et p. 44 et suiv.

34. Le 11 avril 1418 , les gens des comptes pour le roi réalisent une information pour connaître les «franchises et les libertés» de la ville de Falaise afin de les restituer (Puiseux, 1858, nº 109, p. 15-16). Les établissements religieux et charitables sont soumis aux mêmes conditions. Les privilèges de la fraternité des aveugles Saint-Gratien à Bayeux, ceux des lépreux de Sainte-Marie de Beaulieu à Caen et du Mont-aux-Malades à Rouen, sont confirmés les 14 avril 1418, 18 mai 1418 et 3 janvier 1420 (Puiseux, 1858, nº 1414, p. 266, nº 1422, p. 267, nº 1470, p. 270).

35. Puiseux, $1858, \mathrm{n}^{\circ} 302$, p. 54-55 (15 février 1420); De ordinatio monete, $\mathrm{n}^{\circ} 543$, p. 91 (8 mai 1420), $\mathrm{n}^{\circ} 708$, p. 116-117 (décembre 1420); no 1058, p. 188-189 (30 novembre 1422), $\mathrm{n}^{\circ} 1373$, p. 253 (11 avril 1422?); Mollat, 1952, p. 26 et suiv.

36. Newhall, 1929, p. 217 ; Puiseux, 1858, no 1368, p. 252 (18 février 1421).

37. JOUET, 1969, p. 34

38. Certains Normands opposent une résistance farouche à l'Anglais dès 1417 (JouET, 1969, p. 34; Newhall, 1929, p. 210-211). Le 21 mars 1418, Henri V promeut un mandement pour obliger ses «brigands à se soumettre» (PUISEUx, 1858, n 1360, p. 250).

39. LÉCHAUdÉ D’ANISY, 1846, p. 283, col. 1. 
28 juin 1418 à condition de prêter serment de fidélité à l'occupant ${ }^{40}$. Ceci est fait devant «les gens des comptes du roy» le 29 septembre 1418 . Henri V confirme les privilèges l'année suivante. Ce n'est d'ailleurs pas un hasard si ces deux actes se situent respectivement en cinquième et quatrième positions dans le cartulaire de Saint-Nicolas ${ }^{41}$. À Caen, le 14 mars 1419, Edmund Mortimer, comte de la Marche et d'Ulster, lieutenant général du duché de Normandie, confirme le droit pour les lépreux de prendre deux milliers de harengs sur la ferme de la prévôté de Caen le mercredi des Cendres ${ }^{42}$.

Il semble que les années 1420 jouissent d'une très relative prospérité consécutive à la politique de «conciliation » du monarque anglais ${ }^{43}$. Hormis les confins orientaux, la Normandie connaît une période d'accalmie entre 1424 et 1435 : les champs de bataille s'éloignent vers la région parisienne ou l'Orléanais ${ }^{44}$. Toutefois, comme le note Michel Mollat, la circulation commerciale est aussi précaire sur la Seine que sur terre et les routes normandes offrent peu de sécurité à cause de la guérilla incessante ${ }^{45}$. En effet, vers 1432 , se multiplient les ravages des bandes de soldats errants ${ }^{46}$.

Qu'est-ce qui, à partir de 1433, explique la rédaction du cartulaire H suppl. 5034 de Notre-Dame de Beaulieu? Voyons la chronologie et le type d'actes qui entourent la rédaction initiale. Le roi confirme aux habitants de Caen le 17 janvier 1421 tous leurs anciens privilèges dont celui des élus de nommer deux gardes des malades de Beaulieu ${ }^{47}$. Le 25 février 1426, Henri VI restitue aux «bourgeois et manans» leur maison du pont Saint-Pierre ${ }^{48}$. Les procès commencent alors. À la faveur des troubles de l'occupation, certains métiers de Caen et les fermiers de la prévôté ont procédé au dépeçage des droits de la léproserie. Les jurés de la ville reprennent leurs droits au nom de leur ancienne fondation.

Le premier contentieux s'ouvre dès le mois de mai 1426 avec les teinturiers qui ont pris le droit de "guide ${ }^{49}$ » aux lépreux. Une autre source de revenus,

40. Cart. Saint-Nicolas, p. 6, $\mathrm{n}^{\circ} 5$.

41. "... A avoir des dits priour et freres, le serment de feaulté que tenus lui sont faire... ", cart. SaintNicolas, p. $6, \mathrm{n}^{\circ}{ }_{5}$ et p. 5-6, $\mathrm{n}^{\circ} 4$. Il n'en va peut-être pas autant pour la léproserie Saint-Jacques du Bois-Halbout puisque Henri V nomme le 10 avril 1422 Raoul de Vauville, un «collaborateur », comme administrateur de l'établissement (PUISEUX, 1858, nº 1505, p. 273).

42. Caen, Arch. dép. Calvados, H suppl. 5034, fol. 5v-6, nº 10, puis cart. H suppl. 5034.

43. Mollat, 1952, p. 37 .

44. BoIs, 1981, p. 294.

45. Mollat, 1952, p. 50-51.

46. JOUET, 1969, p. 35 .

47. ID., 1981, p. 99.

48. Ibid. Le pont Saint-Pierre enjambait la Petite Orne au sud du chevet de l'église Saint-Pierre pour réaliser la jonction entre la rue Cathehoulle et la rue Exmoisine (actuelles rue de Geôle et rue Saint-Jean). Le pont a disparu entre 1838 et 1857 lors de la canalisation de la Petite Orne sous la terre à l'occasion du creusement du canal de l'Orne vers la mer.

49. Droit à payer sur la ghilde des teinturiers de Caen? Ghilde ou guilde: association d'artisans ou de commerçants pour se prêter assistance et exercer ensemble leur commerce. Le texte incomplet de la coutume des métiers de Caen (1326) n'en dit mot (SAuvage, 1914, p. 1-32). Cart. H suppl. 5034, fol. $12 \mathrm{~V}-13, \mathrm{n}^{\circ} 23$ et 24 . L'affaire se poursuit jusqu'en 1429 . 
celle du droit de «plancage ${ }^{50}$ » fait l'objet d'un contentieux en 1427. Sur chaque cargaison de sel apportée par navire, une « quarte ${ }^{51} »$ doit être livrée aux lépreux ${ }^{52}$. La même année, Notre-Dame récupère «le denier-Dieu de la coutume du poids le roi» à saisir sur toutes les marchandises qui pèsent plus de douze livres et demie $^{53}$, ainsi que la coutume de deux milliers de harengs à prendre sur la prévôté de Caen ${ }^{54}$.

La mise en coupe réglée des privilèges de la léproserie Notre-Dame conduit la municipalité à faire réaliser un cartulaire à partir du 18 août 1433, qui se compose de toutes les pièces disponibles (après 1350), afin de conserver la pérennité de ses droits ${ }^{55}$.

La Normandie, qui connaissait déjà dans les années 1410 le début d'une récession économique par la paralysie du trafic maritime liée aux raids ${ }^{56}$ et les multiples destructions de la conquête ${ }^{57}$, est à partir de 1435 en proie à une crise majeure ${ }^{58}$. Écoutons les doléances des états de Normandie du 3 décembre 1435 adressées à Henri VI:

[...] Pour mouvoir vos nobles courages à pitié et compassion, afin de parvenir à icelle très désirée et nécessaire paix, se faire ce peut, vous plest, souverain seigneur, et vous très nobles et révérens seigneurs, remémorer et avertir la longue, dure et ennoïeuse guerre que les Normans ont soufferte et souffrent, par si lonc temps, comme plus de XX ans, laquelle est entrevenue touzjours de mal en pis; aussi les grans sommes de deniers que iceulx Normans ont païées pour soustenir et conduit icelle guerre; semblablement les griefs, opressions, pertes, domaiges, violences, pilleries, occisions, tiranies, injustices, rançons, apatis et autres extorcions que le povre peuple de Normendie a soustenus et endurés en tous estats, serfs en servage, en espérance de parvenir à la paix, et tant que plus n'en puelt, et mesmement que de présent de toutes pars, par mer et par terre vostre dit païs et duchié de Normendie est avironné, et dedens iceluy païs sont logiés les adversaires qui tous maulx commettent et détruisent le pais; ainsi que de ces choses, iceulx supplians supposent que suffisamment soié informés, tant par experience que parce que et autres foys vous en a esté exposé plus amplement ${ }^{59}$.

50. Étymologie: planche jetée entre le quai de déchargement et le pont du navire.

51. Un quart du sel.

52. Cart. H suppl. 5034, fol. 14-20v, $\mathrm{n}^{\circ} 26$ à 30 .

53. Cart. H suppl. 5034, fol. 11v-12, $\mathrm{n}^{\circ} 22$.

54. Cart. H suppl. 5034, fol. 6-v, $\mathrm{n}^{\circ} 11$.

55. Le 18 août 1433. Cart. H suppl. 5034, fol. 1, nº 1 .

56. JOUET, 1984, p. 227.

57. Neveux, 1996, p. 106-112 et p. 609, tabl. III. Par exemple, la Sainte-Trinité de Caen est abandonnée après 1417. «La léproserie du Nombril-Dieu à Caen est désertée à cause des guerres du royaume de France et dans les parties de la Normandie» (26 février 1420); Denifle, 1897, p. 79.

58. "L'année 1435 sonne le glas de la prospérité sous la domination anglaise» (MolLAT, 1952, p. 52 et suiv.; BoIs, 1981, p. 284-286).

59. Puiseux, $1858, n^{\circ} 1385$, p. 257. 
Le roi répond favorablement à leur requête ${ }^{60}$, mais les exactions se maintiennent à un niveau élevé. La Normandie subit en moins de trente ans une ponction fiscale de quelques 6300 ooo livres tournois ${ }^{61}$.

C'est à la fin de la période de reconstruction qui suit la guerre de Cent Ans que les cartulaires de Notre-Dame de Beaulieu (Hnc 292) et de Saint-Lazare sont rédigés. Les caractères morphologiques de l'écriture permettent de dater le deuxième cartulaire de la léproserie de Caen après le premier tiers du $\mathrm{XV}^{\mathrm{e}}$ siècle. Cette transcription renferme des actes du XIII ${ }^{\mathrm{e}}$ siècle qui appartiennent peut-être à un cartulaire plus ancien ou à des originaux retrouvés. Il ne contient que des donations aux lépreux. Ce manuscrit a sans doute été conçu pour garantir les possessions acquises à une période faste et faire face aux éventuelles prétentions du roi de France après le recouvrement de la Normandie.

Depuis 1317, la léproserie est sous la tutelle de la commune de Falaise. Celle-ci ordonne la rédaction du cartulaire de Falaise en 1487 par crainte d'en perdre l'administration et les revenus au profit de l'aumônier du roi. Les prérogatives de ce prélat ne cessent d'augmenter depuis le règne de Charles VI et empiètent sur le droit de la commune à nommer le prieur ${ }^{62}$. Les cartulaires ont aussi pour but de prémunir les léproseries des exactions fiscales royales en faisant valoir un droit d'immunité ancien. En fait, ce droit a toujours relevé de l'utopie dans la mesure où le souverain décide ou non de son maintien ${ }^{63}$.

Du début du XIII ${ }^{e}$ siècle à la fin du $\mathrm{XV}^{e}$ siècle, la rédaction des cartulaires de léproserie entend sauvegarder des privilèges menacés et garantir les droits de leurs commanditaires.

\section{Commanditaires et rédacteurs}

Il existe deux types de commanditaires. Les prieurs sont les maîtres d'œuvre lorsque les établissements jouissent encore de leur autonomie, sinon ce sont les maires et les bourgeois des communes. Tout comme Falaise, Pont-Audemer reçoit le rang de commune par Philippe Auguste en 1204. La rédaction du cartulaire de Saint-Gilles témoigne peut-être d'une compétition de pouvoir entre la congrégation des lépreux et la commune. Dès 1218, les maire et pairs de Pont-Audemer figurent comme témoins, notamment lors d'entrées dans la maladrerie ${ }^{64}$. Toutefois, il est difficile d'établir une ingérence complète des

60. «Le roy est très malcontent et tant desplésant que plus ne peut, et en a très grant compassion, à quoy par le plésir de Dieu, il mettra et fera mettre telles et si briefves provision que ce sera, à la louange de Dieu, consolation et grant repos des susdis subgez; et cognoit qu'ilz ont été longtems en guerre, et ont besoing de estre allégiez et secourus, ce qu'il désire et veult faire effectuellement par toutes voies et manières possibles» (PuIsEux, 1858, n 1386, p. 258 (23 décembre 1435)).

61. Coville, 1894, p. 244; Robillard de Beaurepaire, 1859, p. 347-541; Doucet, 1926, p. 265-332.

62. JEANNE, 2010b, p. 118-119.

63. SCORDIA, 2004, p. 387-388.

64. Cart. Saint-Gilles, fol. 25v, $\mathrm{n}^{\circ} 73$ (1218), fol. 52, $\mathrm{n}^{\circ} 137$ (1221) et fol. 91v, $\mathrm{n}^{\circ} 157$ (1221). 
autorités communales dans les affaires de Saint-Gilles dans les années $1220^{65}$. On peut donc considérer que c'est le prieur et non la municipalité qui a ordonné la réalisation du manuscrit. La même hypothèse peut être formulée pour le cartulaire de Saint-Nicolas d'Évreux.

Cas rare pour être signalé, Saint-Nicolas de Bayeux conserve son indépendance vis-à-vis de la municipalité car la léproserie bénéficie d'une ardente protection épiscopale. C'est Pierre de Missy, connu dans l'ouvrage comme prieur de Saint-Nicolas pendant 24 ans, entre le 13 juin 1429 et le 12 avril 1453, qui commande le travail:

Dieu devant. En l'an de grace mil quatre cent trente huit, le $\mathrm{XXV}^{\mathrm{e}}$ jour du moys de novembre, religieux homme et honeste messire Pierre de Missy, priour de Saint Nicollas de la maladerie pres Baieux, alors saisy de pluseurs lectres hereditalles deuement signees, seelles et aprouvees saines et entières en seeaulx et en escriptures tant faictes en nom dudit hostel et priouré que es nomps d'autres personnes donq ilx ont le droit et cause, considerant le bien et évident prouffit de lui, ses religieux et de leurs sucessours en icelui priouré du double et extrait d'icelles lettres mot a mot sans y riens mettre ny adjoster, fist icellui priour, par son motif et bon advis, faire cest livre de chartrier collacione aus originaux par moi, Jehan Desmaires ${ }^{66}$, clerc tabellion royal endit an, en la sergenterie de Cerisy ${ }^{67}$ en tant que iceulx doubles et extrais il en est cy après mis, collacioné faite à l'original et signé de mon signe $[\ldots]^{68}$

Depuis la fin du XIII siècle, la municipalité de Caen s'est emparée de l'administration de Notre-Dame. La chose est confirmée par une ordonnance de Charles V en 1364 dans laquelle il est spécifié que les jurés élus nomment deux gardes pour les malades de Beaulieu ${ }^{69}$. Ce sont ces derniers qui ordonnent la rédaction du cartulaire de 1433 :

Le chartrier duquel sont contenus escriptes et desclaries, rentes, revenues et possessions qui sont et appartiennent aux malades de la maladerie Nostre Dame de Beaulieu près Caen, fait en l'an mil quatre cens trente trois, Damien Marguerie, Richart Daguein et Henry Le Fevre de present gardes, administrateurs et gouverneurs d'icelle maladerie, desquelles lettres et chartres je, Guillaume Denis, tabellion pour le roy nostre sire es mectes ${ }^{70}$ des sergenteries d'Argences,

65. Touati, 1993, p. 488 ; Mesmin mac Dougall, 1987, p. 235-267.

66. Jean Desmaires est tabellion royal dans la vicomté de Bayeux. Gardien des registres du tabellionage de son père, Guillaume Desmaires, après la mort de celui-ci en janvier 1417, il est mentionné dans le cartulaire entre le 24 janvier 1417 et le 3 octobre 1453 . Il est connu comme tabellion en la sergenterie de Graye-sur-Mer en 1438 et 1445, en celle de Briquessart en 1445 et en celle de Cerisy-la-Forêt. Il semble cesser son activité en 1460. Neveux, 1996, p. 175 et p. 407 (1421-1460).

67. Dép. Manche, cant. Saint-Clair-sur-Elle, c. Cerisy-la-Forêt.

68. Cart. Saint-Nicolas, p. $1, \mathrm{n}^{\circ} 1$ bis.

69. Caen, Arch. dép. Calvados, 615 E dépôt 3 ; Carel, 1888, p. 107 et p. 109; Carel, 1886, p. 46; Jouet, 1981, p. 80.

70. Bornes, limites, frontières. 
Trouart et $\mathrm{Va}$ (ravil)le, certiffie avoir veues, leues mot après mot et collacioné a icelle. Tesmoings mon saing manuel mis a chascune d'icelle le XVIII ${ }^{\mathrm{e}}$ jour d'aoust, l'an dessus dit ${ }^{71}$.

Cette première page ne comporte aucune indication qui concerne la commande et le rédacteur.

Le temps de la rédaction du cartulaire de la léproserie Sainte-MarieMadeleine de Bolleville ${ }^{72}$ est celui des incertitudes. Les résistants à l'Anglais tentent de s'emparer de Caen en janvier 1435. Les rebelles sont actifs dans le bailliage de Cotentin ${ }^{73}$. Les meilleurs «ports de mer $^{74}$ » normands sont pris par les Français en 1435 et 1436. Le 13 avril 1436, le connétable de France, Arthur de Richemont entre dans Paris. Cinq mois plus tard, commence le 18 septembre la rédaction du cartulaire de Bolleville. C'est sans doute Guillaume III de Guéhebert, abbé de Sainte-Trinité de Lessay ${ }^{75}$ (1423-1461), qui en commande la composition car la léproserie est sous tutelle du monastère bénédictin depuis la fin du XIII ${ }^{\mathrm{e}}$ siècle ${ }^{76}$.

Trois de ces cartulaires sont réalisés par des tabellions, officiers garants - avec le garde du sceau de la vicomté - de l'authenticité des copies. Jean Amechin est le rédacteur de celui de Bolleville, Jean Desmaires celui de Bayeux et Guillaume Denis celui de Caen daté de 1433 (fig. 3). Tous signent la collation des actes. La forme de ces cartulaires est à l'imitation des cartulaires de tabellionage ${ }^{77}$.

\section{Des marqueurs identitaires}

L'écriture est une mise en scène de la conscience de soi ${ }^{78}$. Un cartulaire marque à la fois la dignité et la domination de l'institution qui le produit ${ }^{79}$. Il représente une mémoire collective fixée par l'écrit à un moment particulier de l'histoire d'une léproserie. Tous les cartulaires de léproseries n'émanent pas des fraternités lépreuses car celles-ci se dissolvent après le reflux des donations des années 1240-1280 et avec l'arrivée de valides qui dépassent en nombre la communauté lépreuse des origines ${ }^{80}$. Le seul cartulaire qui émane d'une collectivité lépreuse est celui de Saint-Gilles de Pont-Audemer réalisé avant la mutation du groupe de malades puisque la première rédaction date des années 1214-1215. Les autres cartulaires de léproseries normandes expriment

71. Cart. H suppl. $H_{5034}$, fol. $1, \mathrm{n}^{\circ} 1$.

72. Dép. Manche, cant. La Haye-du-Puits.

73. Neveux, 2008, p. 332.

74. BeAune, 1990, p. 344 .

75. Dép. Manche, chef-lieu de cant.

76. British Library, Add. ms 17307, cartulaire de Bolleville, fol. 9v-10, $\mathrm{n}^{\circ} 37$ (1270) et fol. 12-v, $\mathrm{n}^{\circ} 47$ (1291), puis cart. Bolleville.

77. Touati, 1993, p. 472.

78. DERRIDA, 1972 , p. $84-85$.

79. Chastang, 2009, p. 37.

80. Touati, 1998, p. 631-684; Jeanne, 2010a, t. 3, p. 624-650. 
tantôt l'orgueil municipal (Notre-Dame de Beaulieu à Caen, Saint-Lazare à Falaise), tantôt le "gouvernement maternel ${ }^{81}$ " d'une abbaye (Sainte-MarieMadeleine à Bolleville) ou celui d'un groupe canonial (Saint-Nicolas à Bayeux).

\section{Quelle identité?}

La majorité des cartulaires a été rédigée alors que le groupe des lépreux est passé entre les mains d'une autorité de tutelle. Il est parfois malaisé de savoir s'il existe une préemption de fait par l'institution de tutelle ou si les lépreux souhaitent volontairement une protection par plus puissant qu'eux ${ }^{82}$. Voici deux cas parmi les mieux documentés. Premier exemple, Saint-Lazare à Falaise. Les années 12701280 signent la fin de l'indépendance de Saint-Lazare quand la commune de Falaise se porte caution des transactions ${ }^{83}$. C'est à l'occasion de la calamiteuse soudure de 1317 que les bourgeois décident de restaurer la destination première de la léproserie dont l'effectif des valides l'a emporté sur le nombre des ladres. La commune qui préside à la reconstruction de Saint-Lazare, fait installer sur la nouvelle porte de la léproserie face au champ de la foire de Guibray, ses propres armes pour montrer sa puissance ${ }^{84}$. Dans la même logique de pouvoir, sûre de sa domination contre les prétentions du roi à nommer l'administrateur de sa léproserie, la commune de Falaise fait rédiger un grand cartulaire ${ }^{85}$ d'un prix élevé dans lequel est consigné une réécriture de l'histoire toute à sa gloire ${ }^{86}$ qui fait fi de l'autonomie originelle de la fraternité lépreuse:

... Lesquieulx nous firent exposer comme anciennement par les bons bourgoys qui lors estoient en ladicte ville dudit lieu de Faloise, ladicte maladerie avoit este douce et fondée pour le bien et le salut de l'ame d'eulx et aussy pour le vivre et soustenement des meseaulx et meselles qui estoient lors et qui seront pour le temps advenir es parroisses de la Trinite, Saint Gerves et Guibray. Lesquelx malades estoient recuillez et ne doivent ou povoient aller truander ${ }^{87}$ ou partir de l'ostel sans l'octroy congie ou consentement du maistre ou prieur d'icelui hostel ${ }^{88} \ldots$

81. DALARUn, 2012, p. 279-289.

82. Les lépreux de Saint-Jacques du Bois-Halbout (dép. Calvados, cant. Thury-Harcourt, c. CesnyBois-Halbout) se mettent sous la protection des chanoines de l'abbaye du Val dans le dernier tiers du XII ${ }^{e}$ siècle (Arnoux et MAneuvrier, 2000, p. 16-17; JeAnne, 2010a, t. 2, p. 297).

83. Le dossier de la mutation de Saint-Lazare est traité dans JeAnNe, 2010a, t. 3, p. 669-674.

84. «... Et fait les armes de la ville dudit Faloise avequez deux lyons rampans (...) et un grand carrel a double fieulleure et a fleurs a mectre dessus les dictes armes pour les garder de la pluye avecquez deux corbeaux taillez en forme de deux dragons pour faire la saillie, icelles armes assises entre les deux portes de nouvel faictes es murs de l'aclos dudit hostel sur les champs de foire de Guibray... ", Caen, Arch. dép. Calvados, 386 E dépôt 638, comptes de Saint-Lazare de Guibray, fol. 140 (1479).

85. Comme les moines qui assimilent leurs archives (armarium) à l'arsenal (armamentarium) des châteaux (Morsel, 2000, p. 10, n. 20).

86. Un processus analogue de fabrication d'un roman historique existe dans le cartulaire de SaintSeurin de Bordeaux (Henriet, 2009, p. 139).

87. Truander: mendier.

88. Cart. Saint-Lazare, fol. $132 \mathrm{~V}, \mathrm{n}^{\circ} 238(1424)$. 
Autre cas d'école, celui de Saint-Nicolas à Bayeux. Point de mention de chanoines augustins au départ. Le groupe des lépreux affirme au XII ${ }^{\mathrm{e}}$ siècle son identité par un genre de vie cénobitique ${ }^{89}$ consacré par une dédicace et des donations prestigieuses. La communauté lépreuse est alors autonome ${ }^{90}$. C'est seulement en 1227 qu'apparaît la première mention des chanoines qui prennent en main la destinée de la léproserie ${ }^{91}$. Autour de 1240, la terminologie "hommes religieux", qui désigne le groupe canonial des Augustins, remplace de manière progressive l'assemblée (conventus) des lépreux ${ }^{92}$. Après 1271, la fraternité lépreuse dont l'effectif est devenu inférieur à celui des sains, n'est plus mentionnée ${ }^{93}$. Désormais valide, le prieur prend en charge la léproserie devenue prieuré ${ }^{94}$. La réalisation du cartulaire par Pierre de Missy révèle la place que ce prieur tient à l'intérieur comme à l'extérieur de la léproserie. Son nom revient en effet le plus souvent devant celui de son prédécesseur Nicolas de Caumont (actif entre 1397 et 1428) ${ }^{95}$.

La fabrication de cet ouvrage correspond au besoin de défendre les privilèges face aux spoliations de l'occupant anglais. La répétition des confirmations des libertés octroyées par Henri V montre la difficulté de leur application ${ }^{96}$. Pris dans l'étau des prétentions royales, l'une des solutions qui s'offre au prieur est de faire écrire un cartulaire pour montrer l'ancienneté de la fondation et l'éclat des donateurs, gage de dignité et de renommée du prieuré. Le cartulaire s'ouvre donc sur une confirmation de Henri II Plantagenêt (v. 1170) de dons offerts aux lépreux par Guillaume de Normandie qualifié d'illustris rex Anglorum ${ }^{97}$ par le scribe. La convocation de la memoria de l'ancêtre le plus éminent et de son successeur Plantagenêt, met en valeur la «continuité anglo-normande» des fondateurs ${ }^{98}$. Elle

89. "... Confratribus leprosis in monasterio Sancti Nicholai Baiocas sub religione viventibus sunt», cart. Saint-Nicolas, p. 1, no 2 (1170).

90. «... Nobis, prior et humilis Sancti Nicholai Baiocensis leprosorum conventum, salutem in Domino qui est omnius salus ad universitatis nostre noticiam volumus pervenire nos de communi assensu nostre, dedisse et concessisse... », cart. Saint-Nicolas, p. 16-17, $\mathrm{n}^{\circ} 18$ (1215).

91. "... Priori, conventui domus Sancti Nicholai Baiocensis ordinis beati Augustini...», cart. SaintNicolas, p. 7, no 8 , bulle d'Honorius IV.

92. «... Viros religiosos, priorem et conventum Sancti Nicolai...», cart. Saint-Nicolas, p. 235, n 313.

93. "... Priori et fratribus Sancti Nicolai Baiocensium tam sani quam leprosi... ", cart. Saint-Nicolas, p. 204, $\mathrm{n}^{\circ} 269$ (1271). «... A hommes religieux et honnestes, le priour et les frères sainz de Saint Nicolas...", cart. Saint-Nicolas, p. 618, nº 738 (1319).

94. Première mention attestée en 1248. "... Le priour et les frères de la priourté de Saint Nicolas...", cart. Saint-Nicolas, p. 275, no 367 . Le vocable prieuré s'impose avec les années 1290. Cart. SaintNicolas, p. 515, $\mathrm{n}^{\circ} 635$ (1290); p. $381, \mathrm{n}^{\circ} 510$ (1295). Dans cette logique évolutive, le terme «maladerie» devient à la fin du XIII ${ }^{\mathrm{e}}$ siècle un simple qualificatif placé après la dédicace. «... Priour et as frères de Saint Nicolas de la maladerie... », cart. Saint-Nicolas, p. 659, $\mathrm{n}^{\circ} 789$ (1298). La fraternité des lépreux s'est définitivement éteinte.

95. 35 occurrences contre 31 . Le nom des autres prieurs vient loin derrière.

96. Cart. Saint-Nicolas, p. $6, \mathrm{n}^{\circ} 5$ (1418); p. 25-26, no 26 (1418); p. 32, $\mathrm{n}^{\circ} 41$ (1418); p. 32-33, $\mathrm{n}^{\circ} 4^{2}$ (1418); p. 5-6 no 4 (1419); p. 40-41, no 54 (1420); p. 33, no 43 (1420); p. 3-5, no 3 (1421); p. 33-34, $\mathrm{n}^{\circ} 44$ (1421); p. 25, no 27 (1422); p. 34, no 45 (1422); p. 25-26, no 28 (1423); p. 26, no 29 (1426); p. $27, \mathrm{n}^{\circ} 32(1426) ;$ p. $30-31, \mathrm{n}^{\circ} 38(1427)$; p. $27-28, \mathrm{n}^{\circ} 33$ (1429); p. $28, \mathrm{n}^{\mathrm{o}} 34$ (1429); p. $28-29, \mathrm{n}^{\mathrm{o}} 35$ (1429); p. 29, $\mathrm{n}^{\circ} 36$ (1430); p. 30, $\mathrm{n}^{\circ} 37$ (1433); p. 26, $\mathrm{n}^{\circ} 30(1434) ;$ p. $26, \mathrm{n}^{\circ} 31$ (1437).

97. Cart. Saint-Nicolas, p. 1-3, n ${ }^{\circ} 2$.

98. Morelle, 2009, p. 52-53, p. 60. 
inscrit le patrimoine de Saint-Nicolas dans une tradition longue sous la protection de morts vénérables, que les rois anglais ne sauraient (théoriquement) fâcher ${ }^{99}$. On trouve quatre copies totales ou partielles de cette charte au début du cartulaire ${ }^{100}$. Toutes correspondent à des attaques contre les droits de la léproserie. Le cartulaire de Saint-Nicolas peut surprendre par ses dimensions et son poids $(7,820 \mathrm{~kg})$. Même s'il contient un sommaire, son maniement reste peu pratique. Le travail est minutieux, l'écriture appliquée tranche avec les graphies d'ordinaire hâtives des tabellions ${ }^{101}$. Les domaines sont localisés par ordre alphabétique, souci d'une gestion idoine pour un domaine très morcelé sur un vaste espace ${ }^{102}$. Ce cartulaire témoigne de conceptions composites, un monument pour impressionner, un classement efficace des actes, une fonction mémorielle identitaire importante ${ }^{103}$.

\section{Le cartulaire comme arsenal sacré?}

Un cartulaire est un ouvrage de savoir, de pouvoir et de combat. Il incarne «l'écrit en action: montrer et intimider ${ }^{104}$ ». Un cartulaire peut être envisagé comme un objet rituel et sacré. Les deux sont indissociables. L'écrit est un rituel dans la mesure où il incarne la répétition. Cette réitération fonde l'authenticité des actes ${ }^{105}$. Tout rituel requiert du public. Or, un cartulaire est un objet de communication à l'interface avec le monde extérieur et le personnel de la léproserie. Outil relationnel, il montre et préserve les liens avec les familles des donateurs, les fermiers, les bourgeois de la ville, l'évêque, les agents du roi, les abbayes, les princes. Le rituel permet le retour à la concorde en créant ou en renforçant un lien social après une crise ${ }^{106}$. Mieux, il a pour fonction essentielle d'éviter le retour à la crise sacrificielle qui menace la communauté d'exploser ${ }^{107}$.

Comment définir le sacré? Dispositif de résolution des conflits humains, le sacré sert à créer du consensus ${ }^{108}$. Mais le sacré est inséparable de la violence ${ }^{109}$. En quoi l'écrit serait-il un support de la violence? Parce que l'écriture constitue un pharmakon ${ }^{110}$ (une médecine) aux crises. À la fois remède pour la congrégation attaquée qui défend son identité par l'auctoritas de l'écrit, l'écriture est aussi un poison administré pour légitimer les droits contre la partie adverse ${ }^{111}$.

99. Chastang, 2004, p. 178, p. 187; Geary, 1993, p. 23; Zimmermann, 2004, p. 42.

100. Cart. Saint-Nicolas, p. 1-3, $\mathrm{n}^{\circ} 2$ (1438); p. 3-5, $\mathrm{n}^{\circ} 3$ (1421); p. 21, $\mathrm{n}^{\circ} 23$ (1377) et p. 22-23, $\mathrm{n}^{\circ} 24$ (1407).

101. Bertrand, 2009, p. 91.

102. Le domaine de Saint-Nicolas est circonscrit dans un rayon de $60 \mathrm{~km}$ environ.

103. Bertrand, 2009, p. 83-84.

104. Morelle, 1997, p. 286-29o.

105. Guyotjeannin, 2004, p. 11, p. 14.

106. Offenstadt, 1997, p. 12.

107. GIRARD, 2002, p. 172.

108. BROWN, 2002b, p. 278.

109. Girard, 2002, p. 385.

110. DERRIDA, 1972 , p. 87 , p. 91.

111. La riposte peut s'exercer sous la forme de malédictions ou de sentences d'excommunication, "poisons» répandus avec mesure (MoRelle, 1997, p. 290-296). La fabrication de faux permet aussi de reconstruire et valider un passé conforme à un idéal qui souligne le temps immuable d'une 
La «scripturalité ${ }^{112}$ » est donc sacer, à la fois maudite et vénérée, au sens du latin classique. Peut-on saisir l'efficacité de la «sacralisation de la forme écrite de la parole ${ }^{113}$ " ? La réalisation d'un cartulaire instaure l'unanimité de la collectivité lépreuse ou canoniale contre un ennemi commun pris en dehors d'elle. La «magie ${ }^{114}$ » de l'écriture résiderait peut-être alors dans l'efficacité de sa valeur protectrice qui permet au conventus de retrouver sa cohésion perdue, à la fraternité d'être réordonnée. La ligne qui commence la charte d'authentification du cartulaire de Saint-Nicolas n'indique-t-elle pas «Dieu devant ${ }^{115}$ ?» Cette invocation protège les biens acquis, l'identité de la communauté et le cartulaire, garant de l'ensemble. C'est par dévotion que Pierre de Missy a fait rédiger le cartulaire ${ }^{116}$.

À partir du XIVe siècle, le roi, avec son cortège de revendications, devient l'adversaire le plus fréquent. Par l'écrit, un cartulaire forge une forte identité communautaire alors en péril par un processus de domination ${ }^{117}$. La copie est un aussi acte de charité. La gestion rationnelle des biens offerts grâce au cartulaire permet de conserver la prospérité des léproseries, avec en retour, une redistribution sous forme d'aumônes de denrées aux malades et aux hôtes de passage. Enfin, l'usage du codex sacralise les documents ${ }^{118}$ puisqu'il imite le support de la Bible, écrin des valeurs chrétiennes de la société médiévale ${ }^{119}$. Voyons à présent quelles formes prennent ces cartulaires.

\section{Formes et contenus}

Deux ensembles se dégagent: les gros volumes qui renferment plus de 100 folios: Pont-Audemer et Falaise contiennent respectivement 106 et 261 folios avec des formats respectables ( 230 x $214 \mathrm{~mm}$ et 287 X $295 \mathrm{~mm}$ ). Le plus important de cette catégorie, inclassable pourrait-on dire, est le cartulaire de Bayeux qui cumule les records avec une dimension de $300 \times 350 \mathrm{~mm}, 848$ pages, 992 actes. L'autre groupe est formé par les petits manuscrits, ceux de Notre-Dame de Beaulieu à Caen avec 34 et 46 folios et celui de Bolleville ( 56 folios). Tous ces cartulaires sont incomplets, lacunaires ou inachevés. L'inachèvement est consécutif à l'oubli d'un tabellion, comme l'indique le sommaire du cartulaire de Saint-Nicolas de Bayeux: «En après enssivent aucunes lettres qui ne sont segon l'ordre de la croix de par Dieu donc les unes ont estey oublieez et les autrez ont esté faictes depuis

communauté menacée (Chastang, 2004, p. 189; Guyotjeannin, 2004, p. 19; Zimmermann, 2004, p. 44, p. 53-54).

112. «Recours à l'écriture pour communiquer des informations au lieu de le faire de manière purement orale (on parle alors d'«oralité»)", MORSEL, 1991, p. 411.

113. Guerreau-Jalabert, 1997, p. 329.

114. Morsel, 200o, p. 24-27.

115. Cart. Saint-Nicolas, p. $1, \mathrm{n}^{\circ} 1$ bis.

116. GeARY, 2001, p. 68, p. 70.

117. Guerreau-Jalabert, 1997, p. 338; Morelle, 1997, p. 297 ; Morsel, 2000, p. 21.

118. Chastang, 2006, p. 27.

119. Morsel, 200o, p. 14-15; Chastang, 2008, p. 253. 
que ledit chartier a estey acomply segond la dicte ordre de la croix par Dieu ${ }^{120}$.» Il manque ainsi sept actes entre les pages 803 et 812 . Enfin, la transcription du dernier acte $\left(n^{\circ} 991\right.$, p. 844$)$ - daté entre 1451 et 1453 - est interrompue pour une raison inconnue. Les lacunes des autres cartulaires sont le produit des aléas de conservation (tableau $\mathrm{n}^{\circ}{ }_{1}$ ).

Le plan des manuscrits se développe selon des logiques différentes. Prenons les manuscrits par ordre chronologique.

\section{Saint-Gilles de Pont-Audemer}

Le cartulaire de Saint-Gilles figure parmi les plus anciens conservés pour ce type d'établissements ${ }^{121}$. Jusqu'au folio 35 , les cent quinze premiers actes font mémoire des donations de la famille de Meulan, des confirmations d'offrandes ducales et de privilèges royaux et pontificaux. Les folios 35 à 43 de ce cartulaire renferment une liste des rentes datée entre 1217 et $123 \mathrm{O}^{122}$. Une autre liste (fol. 88v89) est écrite autour de 1219, les recettes prises sur la prévôté de Pont-Audemer ainsi que diverses coutumes dues aux lépreux ${ }^{123}$. On trouve aussi (fol. 43v) une déclaration des barons normands consécutive à l'enquête de Philippe Auguste sur les bénéfices vacants ${ }^{124}$. Les folios qui suivent contiennent des éléments du Tractatus de legibus Angliae de Ranulf de Glanville (1190) et du Très Ancien Coutumier de Normandie (1199) ${ }^{125}$. Les six articles de la coutume portent sur les procédures d'enquête (de stabilitione), de dessaisine (de dessaisina et de nova dessaisina), d'engagement (de feodo vel vadio), du fief d'aumône (de feodo et elemosina) et de la présentation aux églises (de presentatione ecclesiarum) ${ }^{126}$. L'acte suivant est une copie du traité de Lambeth (1217) qui établit la paix entre Henri III et le prince Louis de France ${ }^{127}$. Suit une lettre patente (13 mai 1213) de Jean sans Terre qui fait de l'Angleterre un territoire vassal du pape; elle clôt la crise marquée par l'interdit sur le royaume, l'excommunication du roi (1208) et l'intention d'Innocent III de déposer le monarque ${ }^{128}$. Les folios $54-68 \mathrm{v}$ reprennent de manière incomplète le Compendium in Job de Pierre de Blois et les folios 69-77v comportent les canons (sauf un) du concile de Latran IV $(1215)^{129}$. La diversité de ces documents correspond à l'ajout de nouveaux cahiers, révélateurs d'une volonté de transmettre tout ce qui peut être utile à la gestion et au salut de l'établissement, sans distinction ${ }^{130}$.

\footnotetext{
120. Cart. Saint-Nicolas, p. 14.

121. Avec celui d'Abbeville, du Popelin et de Saint-Lazare de Paris (TouAti, 1993, p. 496-497 (annexe)).

122. Cart. Saint-Gilles, fol. $34 \mathrm{v}-43$.

123. Cart. Saint-Gilles, fol. $88 \mathrm{v}-89, \mathrm{n}^{\circ} 149$; fol. $89 \mathrm{v}, \mathrm{n}^{\circ} 150$; fol. $89 \mathrm{v}, \mathrm{n}^{\circ} 151$ et fol. $89 \mathrm{v}-90, \mathrm{n}^{\circ} 152$.

124. Mollat, 1937, p. 478-480; Baldwin, 1991, p. 388 et suiv.; Baldwin, 1969, p. 1-30.

125. Cart. Saint-Gilles, fol. $43 \mathrm{v}-44, \mathrm{n}^{\circ} 115$.

126. Cart. Saint-Gilles, fol. $44 \mathrm{v}-45 \mathrm{v}, \mathrm{n}^{\circ} 116$.

127. Cart. Saint-Gilles, fol. 46, $\mathrm{n}^{\circ}$ 117. BALDWIN, 1991, p. 421-423.

128. Cart. Saint-Gilles, fol. $47, \mathrm{n}^{\circ} 118$.

129. Cart. Saint-Gilles, fol. 54-68v.

130. Touati, 1993, p. 473-474.
} 
UNE « MACHINA MEMORIALIS ». LES CARTULAIRES DES LÉPROSERIES...

\begin{tabular}{|c|c|c|c|c|c|c|c|}
\hline 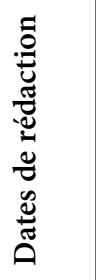 & 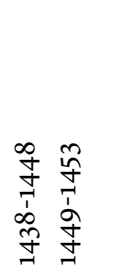 & 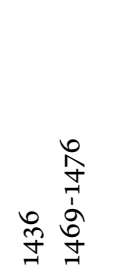 & 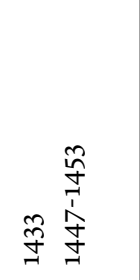 & 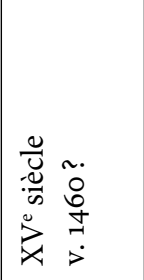 & 命 号 & 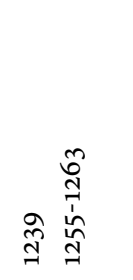 & 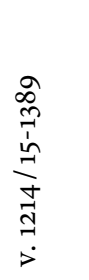 \\
\hline 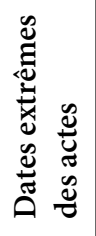 & 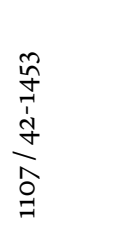 & 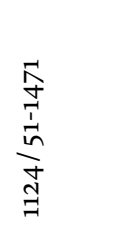 & 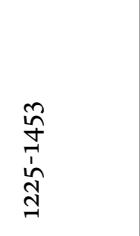 & 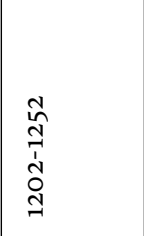 & $\begin{array}{l}\hat{a} \\
\hat{d} \\
\hat{1} \\
\hat{0} \\
0 \\
b \\
\Rightarrow\end{array}$ & 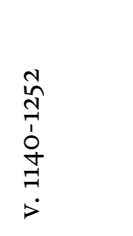 & 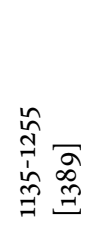 \\
\hline 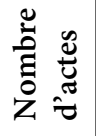 & $\begin{array}{l}7 \\
\bar{a}\end{array}$ & $\stackrel{\infty}{\exists}$ & $\alpha$ & $\infty$ & $\begin{array}{l}+ \\
+ \\
\text { nิ }\end{array}$ & $\begin{array}{l}7 \\
+ \\
0 \\
a\end{array}$ & $\underset{d}{*}$ \\
\hline 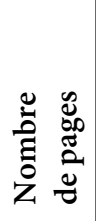 & 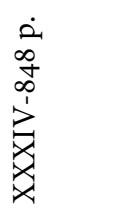 & $\begin{array}{l}\overrightarrow{0} \\
\stackrel{0}{0}\end{array}$ & 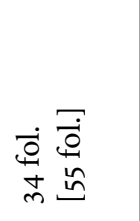 & 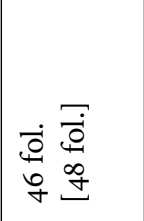 & 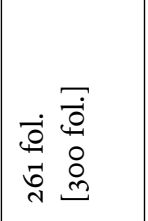 & 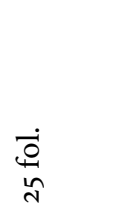 & $\begin{array}{l}\dot{0} \\
0 \\
0 \\
0\end{array}$ \\
\hline 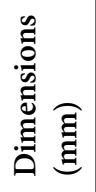 & 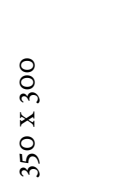 & $\begin{array}{l}\stackrel{8}{\circ} \\
\stackrel{x}{x} \\
\text { त̂ }\end{array}$ & 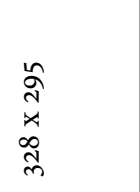 & \begin{tabular}{l}
$\hat{\infty}$ \\
$\vec{x}$ \\
$\hat{ٌ}$ \\
\multirow{n}{*}{}
\end{tabular} & 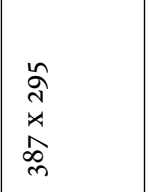 & 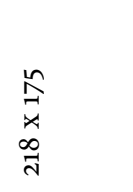 & 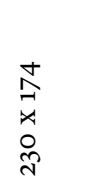 \\
\hline 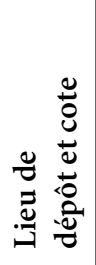 & 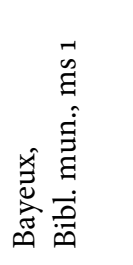 & 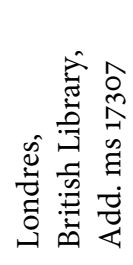 & 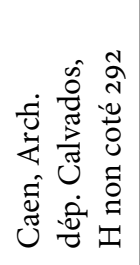 & 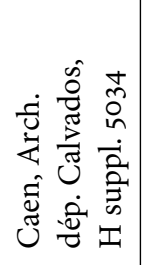 & 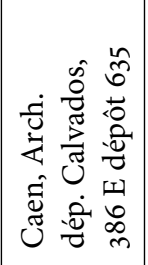 & 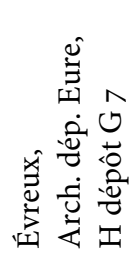 & 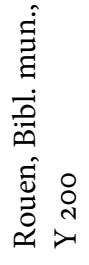 \\
\hline 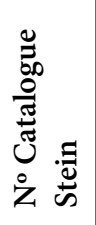 & $\begin{array}{l}\circ \\
\stackrel{0}{m} \\
m\end{array}$ & $\tilde{n}$ & 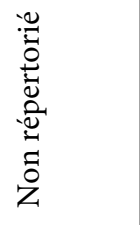 & 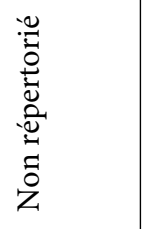 & 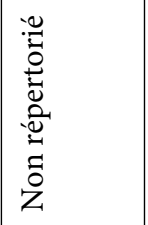 & बे & 㑒 \\
\hline 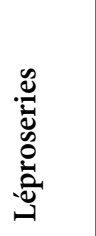 & 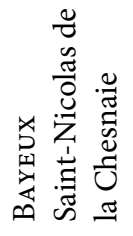 & 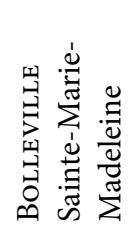 & 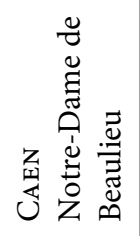 & 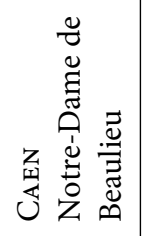 & 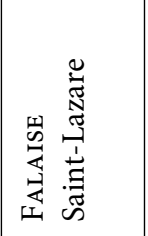 & 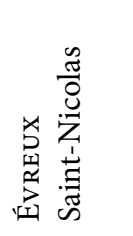 & 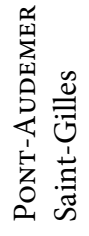 \\
\hline
\end{tabular}


D’autres précisions apparaissent après 1220 . Les scribes mentionnent désormais l'année, puis le mois et les composantes de la communauté lépreuse sous le terme collectif de sains et de lépreux. Rares sont les individus mentionnés comme lépreux ou valides. On rencontre le lépreux lorsqu'il fournit une donation lors de son entrée. Cette «nouvelle mutation documentaire ${ }^{131}$ » révèle une société davantage normée à la fois par l'Église ${ }^{132}$, par les compilations de droit ${ }^{133}$ et par la montée du pouvoir royal ${ }^{134}$. Par cette nouvelle donne juridique, des institutions tant laïques qu'ecclésiastiques tendent à entamer l'autonomie des léproseries en recourant à des procès de plus en plus fréquents avec la dégradation de la conjoncture.

\section{Saint-Nicolas d'Évreux}

Le cartulaire d'Évreux commence par la copie d'une donation de terres proches de la léproserie concédée par Philippe Auguste. Viennent après une confirmation d'un jour de foire de la part du comte du lieu, des donations diverses d'aristocrates en vue, dont Roger de Tosny qui offre le pacage des porcs en sa forêt de Conches. Garin de Cierrey, évêque d'Évreux (1193-1201), confirme le patronage de deux églises. C'est ensuite au tour de la petite aristocratie locale de donner. Peu de grands sont présents. À partir de 1234, certains actes portent la mention de sceaux. Ce cartulaire écrit à trois mains, consigne en majorité la confirmation de quelques droits.

\section{Sainte-Marie-Madeleine de Bolleville}

Conservé à Londres à la British Library (Add. ms 17307), le cartulaire de SainteMarie-Madeleine de Bolleville est le seul fabriqué pour une léproserie rurale. Les sources du cartulariste proviennent de plusieurs documents dont un ou plusieurs cartulaires ou chartriers, comme l'indique l'intitulé: «Cy ensuit la declaration et double de pluseurs chartriez, lettres, roulez et ensignemens de partie des droyctures appartenantes a la priourey de Bollevile ${ }^{135}$ ». Ce qui explique peut-être la volonté de copier à l'identique un ancien cartulaire par l'imitation de la graphie du XIII ${ }^{e}$ siècle, en conservant les lettrines rouges des actes les plus anciens (1151-1291). Cette copie est réalisée par une première main (fol. 1 à $20 \mathrm{~V}-$ actes $\mathrm{n}^{\circ} 1$ à 78 ). On en décèle cinq autres (fol. 20v-25v; fol. 25V-29v; fol. 30-34; fol. 34-49v et fol. 50-55v).

Les actes sont consignés sur parchemin. Ils ne sont pas assemblés par paroisse, ce qui est exceptionnel pour les cartulaires de léproseries de la province

131. BARthéLemy, 1993, p. 19; BAtes, 2003, p. 33-49.

132. Notons, par exemple, le concile provincial de Rouen (1214) et le concile de Latran IV (1215).

133. La Summa de legibus est rédigée à partir de 1223.

134. La mise en place des baillis chargés d'appliquer la justice publique dans les années 1190 (BALDWIN, 1991, p. 285 et suiv.).

135. Cart. Bolleville, fol. 1. 
ecclésiastique de Rouen. Viennent en premier lieu les donateurs prestigieux (les familles de La Haye, du Hommet). Suivent les confirmations des donations précédentes par le roi d'Angleterre Henri II (acte $\mathrm{n}^{\circ}$ 6) et les évêques normands (dont l'archevêque de Rouen Hugues d'Amiens). Suivent d'autres donations, une bulle du pape Honorius III (acte $n^{\circ} 77$ ) qui protège les acquêts des lépreux.

On peut classer les actes en trois groupes chronologiques. Le premier correspond au XIII ${ }^{\mathrm{e}}$ siècle qui recense $47,45 \%$ du total des transcriptions, viennent ensuite les actes du XV $\mathrm{XV}^{\mathrm{e}}$ siècle $(28,81 \%)$, puis les actes du XII $\mathrm{X}^{\mathrm{e}}$ siècle $(21,18 \%)$ et ceux du XIV ${ }^{\mathrm{e}}$ siècle $(2,54 \%)$. Cette proportion est étonnante. Comment expliquer la répartition chronologique des actes et l'absence de toute transcription de procès pour interpréter l'usage de ce cartulaire? Trois fonctions principales se dégagent: la première est d'honorer la mémoire des bienfaiteurs les plus illustres; les deux autres, de montrer l'ancienneté de la léproserie et son gouvernement par l'abbaye de Lessay. Ce cartulaire n'est donc pas un outil de gestion, c'est une "machina memorialis ${ }^{136}$ ", dont le cas n'est pas unique. Le cartulaire de l'abbaye Saint-Martin de Mondaye rédigé au début des années 1240, offre un rôle similaire ${ }^{137}$.

\section{Saint-Nicolas de Bayeux}

Les 845 pages de parchemin du cartulaire de Saint-Nicolas se composent des réglures recto verso de $240 \times 205 \mathrm{~mm}$ avec des intervalles de $5 \mathrm{~mm}$. Chaque page comporte entre 35 et 40 lignes. Ce cartulaire se divise en deux parties inégales. La première partie, qui couvre les 42 premières pages et les 54 premiers actes, fait mémoire de tous les privilèges du lieu. La première transcription est une copie d'une charte de Henri II Plantagenêt écrite en 1170 qui confirme une donation faite à une date inconnue par Guillaume de Normandie de vingt prébendes aux lépreux. Suivent les confirmations du temporel par Henri V Lancastre (1419), des privilèges donnés par Philippe IV le Bel (1304), sept bulles pontificales (la première date de 1175), dont les deux dernières concernent le patronage d'une chapelle dont le procès se finit par une lettre de l'évêque de Bayeux, Nicole du Bosc, qui appuie les prétentions de l'établissement au sujet de la dite chapelle (1402). Viennent trois confirmations royales par Philippe III et Philippe IV $\mathrm{du}$ patrimoine de Saint-Nicolas, puis quelques contentieux, une exemption de taille (1351). Ces chartes remplissent les vingt premières pages. Celles qui suivent (actes 23 à 38) concernent les privilèges sur les bois environnants que la léproserie défend avec passion contre l'édit de Melun (1376) sur les droits d'usage des forêts et les réformateurs chargés de les faire appliquer. Les actes qui suivent reviennent sur les exemptions de taille et les libertés de Saint-Nicolas contre l'occupant anglais. Du $1^{\text {er }}$ au 23 novembre 1387, l'évêque de Bayeux dépêche Henri Oresme pour diligenter une enquête sur la situation de l'établissement qui ne semble pas,

136. Carruthers, 2002a.

137. ThéBault, 2011, p. 43. 
aux dires des témoins, au mieux de sa forme financière (actes 46-52). L'acte qui suit est un procès entre l'évêque et le bailli sur la présentation du prieur. Celui-ci vient de décéder et le roi veut récupérer le bénéfice. Après avoir pris conseil auprès de quatre prêtres desservant les cures proches de Saint-Nicolas et de quatre chevaliers, il s'avère que l'évêque dispose bien du droit de présentation ${ }^{138}$. Ce premier ensemble s'achève par la transcription d'un acte de reconnaissance de l'identité de la léproserie menacée de destruction par l'occupant anglais ${ }^{139}$. Pas moins de quarante-et-un bourgeois rapportent sous serment devant le vicomte de Bayeux rallié aux Anglais ${ }^{140}$ que Saint-Nicolas accueille les lépreux nés dans l'enceinte de la ville. Les bayeusains expliquent que les malades vivent de manière religieuse sous la direction de cinq chanoines qui, « de grant antiquité» assurent les «prioères et orezons pour le roy nostre souverain seignour» et administrent avec efficacité les biens de la communauté. Ils attestent de l'ancienneté de la fondation par les rentes offertes par «feu très noble et très excellent prince, Henri roy d'Angleterre et duc de Normandie», manière pour eux de se concilier les bonnes grâces de l'occupant pour défendre l'existence de Saint-Nicolas ${ }^{141}$.

La deuxième partie du cartulaire (p. 42-844) compile, par ordre alphabétique des paroisses, tous les actes qui concernent les biens du prieuré (les dons, les baux à ferme, les «relaches ${ }^{142}$ » de rente, etc). Cette partie s'ouvre sur une série de quatre croix de Jérusalem. La symbolique de la croix figure le sacrifice de la communauté canoniale - idéal d'imitatio Christi - qui s'est offerte à Dieu pour servir les plus faibles des malades, les lépreux ${ }^{143}$. La croix de Jérusalem évoque l'espace de la cité idéale de saint Augustin, espace de paix que «nul adversaire ne troublera ${ }^{144} »$. Le dessin des croix de Jérusalem montre avec solennité que le patrimoine des lépreux est davantage un bien de l'Église universelle qu'un honor ${ }^{145}$, et que la communauté de Saint-Nicolas - véritable Jérusalem céleste sur terre - entend se maintenir contre l'adversité. Après une brève description de la réserve (terre en faire-valoir direct à l'origine), suivent les 936 actes de donations diverses en échange de messes, d'accueil dans la fraternité de prières, de vente de rente, de contrats de "donnés», de pensionnés, les abandons de terre, etc. Ces actes sont classés par ordre à la fois topographique et alphabétique des 60 localités-paroisses ${ }^{146}$ sur lesquelles s'étendent les biens de Saint-Nicolas. La rédaction s'est déroulée en trois phases d'inégale amplitude: entre le 24 novembre 1438 et le 12 décembre 1448 ,

\footnotetext{
138. Cart. Saint-Nicolas, p. 39-40, $\mathrm{n}^{\mathrm{o}} 53$ (1373).

139. Cart. Saint-Nicolas, p. 40-41, no 54 (1420).

140. Neveux, 1996, p. 185 , n. 525.

141. «Et aveques ce, nous distrent et rapporterent iceulx bourgois et habitans que les diz religieux avoient tousjours bien fait la dicte administration et le divin service endit hostel et en estoient bien contens et sy savoient bien que se lesdiz religieux ne faisoient la dicte administration que tantost ledit hostel et maladerie de Saint Nicolas et les drois qui y appartiennent seroient mis a destrution", cart. Saint-Nicolas, p. 41, n 54 .

142. Diminution de la rente quand celle-ci est de peu de bénéfice.

143. VAUCHEZ, 1994, p. 106, p. 119, p. 123-124.

144. Saint Augustin, 1994, t. 3, XIX, 10, p. 115.

145. Chastang, 2004, p. 201.

146. Localité qui possède une ou plusieurs paroisses (LE BlÉvEC, 200o, p. 598).
} 
1449, puis entre 1452 et le 3 octobre 1453. Cinq scribes différents se sont partagés un travail inachevé, comme l'atteste la table des matières réalisée après coup en 24 pages situées en tête de l'ouvrage. Il manque cinq actes et la dernière copie est incomplète ${ }^{147}$.

\section{Saint-Lazare de Falaise}

Le manuscrit de Saint-Lazare de Falaise est le seul qui soit réalisé avec un bifeuillet de parchemin enserrant huit cahiers formés de papier. Ce cartulaire souffre d'importantes lacunes: sur 300 feuillets, il en manque 39, dont 19 au début de l'ouvrage. Il était encore intact sous Charles X.

... L'ancien matrologue de Saint-Lazare, manuscrit in-folio, relié en bois, commençant en 1422 et finissant en 1484. En tête est une charte en parchemin, de Henri II, roi d'Angleterre; les sceaux en ont disparu; on y trouve les noms d'une foule de barons de la cour du prince, et on y remarque, entre autres, celui d'un Guillaume de Courcy ${ }^{148}$.

La charte du Plantagenêt évoquée par Frédéric Galeron en 1826 ainsi que les ais ${ }^{149}$ ont aujourd'hui disparu. Mais copié par l'abbé Langevin, l'acte d'Henri II révèle une partie de l'organisation interne de l'établissement ${ }^{150}$. Les huit premiers folios et les actes $n^{\circ} 361$ à 364 sont très endommagés et ne permettent qu'une restitution partielle du manuscrit. Les copies sont classées par paroisse. Les paroisses urbaines viennent en premier: Sainte-Trinité ${ }^{151}$; Saint-Gervais ${ }^{152}$ et Notre-Dame de Guibray ${ }^{153}$, suivies de vingt-trois paroisses rurales ${ }^{154}$. Suivent les coutumes, les droits et usages, l'aveu du temporel et les rentes habituelles.

147. Cart. Saint-Nicolas, p. 14 et p. 804

148. Galeron, I, 1826, p. 366-367, n. 2.

149. Ais: planchettes de bois ou feuilles de carton attachées aux nerfs de la couture; ils protègent le volume et servent de supports à la couverture.

150. LANGEVIN, 1814 , p. 89-90.

151. Actes $n^{\circ} 1$ à 104 .

152. Actes $n^{\circ} 105$ à 170

153. Actes $\mathrm{n}^{\circ} 171$ à 255 .

154. Saint-Laurent, dép. Calvados, chef-lieu de cant., c. Falaise ( $\mathrm{n}^{\circ} 256$ à 277); Vesqueville, dép. Calvados, cant. Falaise-Sud, c. La Hoguette, (n 278 à 279); Versainville, dép. Calvados, cant. Falaise-Sud ( $n^{\circ} 280$ à 305); Aubigny, dép. Calvados, cant. Falaise-Nord ( ${ }^{\circ} 306$ à 307); Éraines, dép. Calvados, cant. Falaise-Sud (n 308 à 319); Saint-Pierre-Canivet, dép. Calvados, cant. Falaise-Nord ( $\mathrm{n}^{\circ} 320$ à 323); Noron-l'Abbaye, ibid. (nº 324 à 326); Saint-Pierre-du-Bû, ibid. $\left(n^{\circ} 327\right.$ à 335); Fourneaux-le-Val, ibid. (nº 336); Bazoches-au-Houlme, dép. Orne, cant. PutangesPont-Crépin ( ${ }^{\circ} 337$ à 340); Neuvy-au-Houlme, ibid. (nº 342 à 345); Morteaux, dép. Calvados, chef-lieu de cant., c. Morteaux-Coulibœuf (nº 346 à 347); Ners, dép. Calvados, cant. Falaise-Sud, c. Pertheville-Ners ( $n^{\circ} 348$ à 361 ); Pertheville, ibid. ( $n^{\circ} 365$ à 372); Fourches, dép. Calvados, cant. Morteaux-Coulibœuf ( $n^{\circ} 373$ à 375); Crocy, ibid. ( $\left.n^{\circ} 376\right)$; Merri, dép. Orne, cant. Trun ( $n^{\circ} 377$ ); Cossesseville, dép. Calvados, cant. Thury-Harcourt ( $\left.{ }^{\circ} 378\right)$; Jort, dép. Calvados, cant. Morteaux-Coulibœuf ( $n^{\circ} 379$ à 385); Pont, ibid., c. Vendeuvre ( ${ }^{\circ}$ 386-387); Caudecotte, dép. Calvados, cant. Morteaux-Coulibœuf (n 388-389); Ommoy, dép. Orne, cant. Trun ( $\left.n^{\circ} 390\right)$. 
Le cartulaire se clôt sur les actes de deux longs procès relatifs à la présentation du curé à Morteaux ${ }^{155}$ et à la nomination de l'administrateur ${ }^{156}$.

\section{Formes et normes}

Par chance, les Archives du Calvados conservent un certain nombre de comptes de la léproserie Saint-Lazare. Celui de 1487 consigne la dépense engagée pour la fabrication du cartulaire:

Audit administrateur, la somme de XV livres a luy tauxée par l'oppinion des auditeurs de ce present compte pour avoir fait encartulairer un grant livre en fourme de matrologe couvert d'aes ${ }^{157}$ toutes les lectres, les chartres ensaigemens et instrumens de la revenue et previlleges dudit hostel par chappitres et parroisses chascun par ordre pour ce affin de congnoistre au vraye la revenue et droictures dudit hostel avec les charges prinses sur ledit hostel, lequel livre est fait de grant papier Lambart ${ }^{158}$ et a chascun caier, une peau de parchemin pour garder les caiers de rompre ou pourriture, bien relié et couvert de cuir rouge, enquel a III feuilletz, tant de papier que de parchemin, du nombre desquieulx, y a dix peaux en parchemin en XX feuilletz et le demourant des fieulletz dudit papier ainxi qu'il a este veu par la presentation et rendue que en a faicte ledit administrateur en la reddicion de ce compte pour estre mis en seurté pour le prouffit et utilité dudit hostel en temps advenir, lequel livre ou matrologe, ledit administrateur a fait estaplir ${ }^{159}$ et appoincter ${ }^{160}$ et mesfin fait apporter le pappier dont il est fait de la ville de Paris. Pour cecy, par ladicte ordonnance desdits auditeurs, ladite somme de XV livres ${ }^{161}$.

Le travail est soigné. La dimension du papier dit Lombard ( 387 X $295 \mathrm{~mm}$ ) est remarquable pour le $\mathrm{XV}^{\mathrm{e}}$ siècle. Les papiers français de cette période sont de taille généralement plus modeste ${ }^{162}$. La vergeure ${ }^{163}$ est fine $(1 \mathrm{~mm})$ et les pontuseaux ${ }^{164}$

155. Actes $\mathrm{n}^{\circ} 392$ à 395 .

156. Acte $\mathrm{n}^{\circ} 396,1484$

157. Sic pour ais. Cette reliure de bois existait encore en 1826 (GALERON, 1826, I, p. 365, n. 2). Elle a aujourd'hui disparu.

158. Sic pour Lombard. Papier à l'origine importé en France par les Lombards, mais ici la fabrication est parisienne. Papier Lombard: 487 x $577 \mathrm{~mm}$. La taille est fixée par arrêt du Conseil d'État le 18 septembre 1741. BRIQUeT, 1923, I, p. 6 et p. 12.

159. Estaplir: façonner.

160. Apointier: fournir, ordonner, commander, décider.

161. Caen, Arch. dép. Calvados, 386 E dépôt 638, comptes de Saint-Lazare de Guibray, fol. 360 (1487).

162. Entre $320 \times 460$ et $305 \times 430$ mm (BRIQUET, 1923, I, p. 4).

163. Vergeure: lignes du papiers produite par les fils de laiton de la forme qui retiennent la pâte suspendue dans l'eau et qui, en la retenant, y déposent leur empreinte (BRIQUET, 1923, I, p. 7).

164. Pontuseaux: bâtonnets de bois, taillés en arête et placés dans la forme, perpendiculairement aux fils vergeurs pour les empêcher de fléchir. Mais ces bâtonnets seuls ne laisseraient pas de trace sur le papier. L'empreinte, qui se voit presque toujours distinctement, est produite par un fil métallique tendu par-dessus les fils vergeurs; il les serre contre le bâtonnet en bois et les empêche de se déplacer ou de se chevaucher les uns sur les autres (BRIQUET, 1923, I, p. 8). 
sont espacés de 350 à $300 \mathrm{~mm}$. Deux filigranes sont visibles. Le premier en forme d'ancre ${ }^{165}$ indique en général un papier de grande dimension ${ }^{166}$ (fig. 4 et 5).

\begin{tabular}{|l|l|l|l|l|}
\hline 5,8 & 0,6 & 3,5 & 16,4 & 0,8 \\
\hline & & & Intervalle entre les lignes: 0,8 & \\
\hline & & & Dimensions de la feuille: $39,6 \times 29$ & \\
\hline
\end{tabular}

Réglures du cartulaire de Saint-Lazare de Falaise $(\mathrm{en} \mathrm{cm})$

L'emploi de l'ancre en France est mentionnée pour la première fois en 1391 et se maintient jusqu'en 1484 sans se modifier de manière sensible. C'est le symbole chrétien de l'espérance dans le salut ${ }^{167}$. Le globe terrestre surmonté d'une croix auquel est attaché l'ancre ${ }^{168}$, désigne aussi l'ancrage universel de la foi chrétienne. Les pages du dernier cahier disposent d'un filigrane qui représente un pot d'étain à anse avec couvercle surmonté d'un crucifix ${ }^{169}$. Il révèle un papier en provenance de Champagne ${ }^{170}$. La distance entre les pontuseaux est plus régulière $(3,4 \mathrm{~cm})$. Sept cahiers subsistent dont le premier est très incomplet. On discerne deux mains et une troisième pour l'acte de 1497 copié en 1610 (acte $n^{\circ} 375$ ).

\begin{tabular}{|l|l|l|}
\hline $2 \mathrm{~cm}$ & $11 \mathrm{~cm}$ & $5,6 \mathrm{~cm}$ \\
\hline & Intervalles de $0,6 \mathrm{~cm}$ & \\
\hline
\end{tabular}

Dim. feuille: $18,3 \times 26,5 \mathrm{~cm}$.

Réglures du Hnc 292

\begin{tabular}{|l|l|l|l|}
\hline $4 \mathrm{~cm}$ & $0,5 \mathrm{~cm}$ & $22,8 \mathrm{~cm}$ & $3,5 \mathrm{~cm}$ \\
\hline & & Intervalles: $0,5 \mathrm{~cm}$ & \\
\hline
\end{tabular}

Dim. feuille: $32,2 \times 30,4 \mathrm{~cm}$.

Réglures du H suppl. 5034

165. Filigrane: empreinte laissée en creux dans la feuille de papier par un ornement en fil de métal fixé sur la forme (BRIQUET, 1923, I, p. 8).

166. Ibid., p. 36.

167. CABrol et LeCLerCQ, 1924, col. 2000-2001.

168. Briquet, 1923, I, p. 38 et n $n^{\circ} 393$ ( 395 x 580 mm); source: Paris, 1479, Arch. nat., $\mathrm{Z}^{1 \mathrm{H}}$ 19, Bureau de la ville. Audiences.

169. BRIQUET, 1923, IV, p. 628 et no 12496 (300 x $430 \mathrm{~mm}$ ); source: Cologne, 1485 , Stadtarch, Briefbuch, $\mathrm{n}^{\circ} 34$ et $\mathrm{n}^{\circ} 35$.

170. Le règlement français de 1741 signale le «pot» comme un format de papier $392 \times 311 \mathrm{~mm}$, dont la rame pèse entre 4,4 à 4,9 kg (BRIQUET, 1923, IV, p. 625). 
Le cartulaire de Notre-Dame de Beaulieu (H suppl. 5034) est copié par deux mains en deux temps, l'une entre 1433 et 1447 (fol. 1 à 33) et l'autre de 1447 à 1453 (fol. 33 à 46v). Le deuxième cartulaire (Hnc 292) ne comporte qu'une seule main. On observe tous les $0,8 \mathrm{~cm}$ des points de piqûre sur la première page à droite. Ce cartulaire possède encore sa reliure de cuir sur bois estampé de léopards (fig. 6).

Le premier acte comporte une lettrine ornée rouge et bleu. Les chartes sont toutes du XIII ${ }^{e}$ siècle. Le travail du copiste est original. Il a traduit en français tous les actes écrits originellement en latin en laissant les mots qu'il n'a pu traduire.

\begin{tabular}{|l|r|r|r|r|r|r|}
\hline & $\begin{array}{l}1101- \\
1200\end{array}$ & $\begin{array}{l}1201- \\
1300\end{array}$ & $\begin{array}{l}1301- \\
1400\end{array}$ & $\begin{array}{l}1401- \\
1500\end{array}$ & $\begin{array}{l}\text { Indéter- } \\
\text { minée }\end{array}$ & \multicolumn{1}{l}{ Total } \\
\hline Bayeux & 12 & 125 & 475 & 380 & 0 & 992 \\
\hline Bolleville & 25 & 56 & 3 & 34 & 0 & 118 \\
\hline Caen (Hnc 292) & 7 & 85 & 0 & 0 & 0 & 92 \\
\hline Caen (H suppl. 5034) & 0 & 5 & 16 & 61 & 0 & 82 \\
\hline Évreux & 23 & 70 & - & - & 4 & 97 \\
\hline Falaise & 10 & 69 & 146 & 169 & 2 & 396 \\
\hline Pont-Audemer & 61 & 123 & 0 & 0 & 43 & 227 \\
\hline Totaux cumulés & 138 & 533 & 640 & 644 & 49 & 2004 \\
\hline
\end{tabular}

Tableau no 2 : répartition chronologique des actes des cartulaires de la province ecclésiastique de Rouen

\begin{tabular}{|l|r|r|r|r|l|r|}
\hline & $\begin{array}{l}1101- \\
1200\end{array}$ & $\begin{array}{l}1201- \\
1300\end{array}$ & $\begin{array}{l}1301- \\
1400\end{array}$ & $\begin{array}{l}1401- \\
1500\end{array}$ & $\begin{array}{l}\text { Indéter- } \\
\text { minée }\end{array}$ & Total \\
\hline Bayeux & 12 & 75 & 18 & 11 & 0 & $\mathbf{1 1 6}$ \\
\hline Bolleville & 25 & 56 & 0 & 1 & 0 & $\mathbf{8 2}$ \\
\hline Caen (H suppl. 5034) & 0 & 5 & 0 & 0 & 0 & 5 \\
\hline Évreux & 23 & 70 & - & - & 4 & 97 \\
\hline Falaise & 10 & 65 & 4 & 1 & 2 & 82 \\
\hline Pont-Audemer & 61 & 123 & 0 & 0 & 43 & 227 \\
\hline Totaux & 131 & 394 & $\mathbf{2 2}$ & 13 & 49 & 609 \\
\hline
\end{tabular}

Tableau $\mathrm{n}^{\mathrm{o}} 3$ : répartition chronologique des actes en latin

\section{Conclusion}

Les cartulaires des léproseries sont des sources peu fréquentes. Ils méritent des éditions critiques. Leur apport est multiple pour la connaissance des sociétés 
médiévales. Ces cartulaires sont au cœur de la gestion des conflits dans une société sans État ${ }^{171}$. Conservatoires des droits, les cartulaires sont aussi des révélateurs de changements par les mutations des vocables qui désignent l'arrivée ou la disparition de groupes d'individus lépreux ou valides au sein des léproseries. Tandis que l'on voit disparaître le latin dans les années $128 \mathrm{o}$ au profit du français pour les actes qui n'émanent pas des chancelleries épiscopales ${ }^{172}$, les mots des chartes dévoilent aussi des influences linguistiques diverses. Les héritages des langues nordiques et saxonnes («delle», «croute», «darie», «claim», «codecotte», «vaindinq» ou «hollant») mériteraient, par exemple, une étude à part entière ${ }^{173}$.

La fabrication des cartulaires a pour but de préserver les droits et les patrimoines de toute atteinte. Rédiger un cartulaire consiste à répéter une parole donnée consignée par un premier écrit ${ }^{174}$. C'est donc un rituel qui répond à une crise. Ce rite consiste à regrouper tous les documents disponibles d'une institution pour enrayer l'attaque de ses privilèges et préserver la memoria des donateurs ${ }^{175}$. Mais ici, ce processus se solde par un échec. Malgré le soin avec lequel ces manuscrits ont été réalisés et le lustre que confèrent ces ouvrages - le prix ou la taille - cela n'a pas empêché les léproseries de perdre leur fonction initiale. Après 1220, le nombre des valides l'emporte sur celui des malades.

En 1420, Saint-Nicolas de Bayeux semble en sursis. Depuis des années, la maladrerie n'héberge plus aucun lépreux ${ }^{176}$. Face à la pression de l'occupant anglais qui menace l'existence de la communauté canoniale, les officiers et les bourgeois supplient l'évêque de Bayeux pour que celui-ci intercède auprès des chanoines afin qu'ils hébergent des lépreux. L'évêque et le prieur promettent de «retirer et mettre les hommes, les femmes dedans l'enclos d'icelle ville de Bayeux selon qu'ils seroient esprins ou entaches de la malladie de lèpre». Ils consentent "pour le temps qu'il lour plairoit, recepvoir lépreux sans préjudice, ny force a l'advenir, synon pour lour bon plaisir ${ }^{177}$ ». L'assemblée lépreuse ayant disparu

171. Du XIII au XVe siècle, la puissance du prince était théoriquement absolue et pratiquement limitée (BEAUNE, 1996, p. 11). L'usage de l'État, au sens actuel, en français, ne s'affirme pas avant le temps de Richelieu (Chaunu, 1993, p. 15). «La finalité du gouvernement n'est pas d'imposer une loi aux hommes mais de disposer de choses. » Il faut attendre la fin du XVIII ${ }^{e}$ siècle pour que l'art de gouverner accède au rang de science politique (DALARUN, 2012, p. 285-286). En outre, le degré d'impact d'un État pourvoyeur dans lequel entre en scène le « roi de la troisième fonction» est bien faible lors de la guerre de Cent Ans. L'État est davantage perçu comme un intrus, voire un prédateur plutôt qu'un secours. Le "gouvernement par la grâce» d'un roi qui s'affirme comme la providence de ses sujets n'est efficient qu'à titre individuel par l'octroi de lettres de rémission et par la levée de l'impôt! Les solidarités se conjuguent encore à l'ombre des clochers. La figure du roi arbitre des conflits n'apparait pas dans les cartulaires étudiés (JEANNE, 2010b, p. 112-123; GAUVARD, 2010, p. 63-76; SCORDIA, 2004, p. 199 et suiv.).

172. Lusignan, 2004, p. 47, p. 58-59.

173. NAVEL, 1937, p. 435; Musset, 1997, p. 457-458; RIDEL, 2009, p. 192.

174. Derrida, 1972, p. 115, p. 137, p. 142-143; MoRelLe, 1993, p. 91-102; ID., 2009, p. 55-65.

175. Carruthers, 2002b.

176. «... Combien que par pluseurs ans, la dicte maladerie eust este vuide sans y avoir ladres...", cart. Saint-Nicolas, p. $41, \mathrm{n}^{\circ} 54$.

177. Caen, Arch. dép. Calvados, bibliothèque du chapitre de Bayeux, ms 207, Livre noir de l'évêché, fol. 28 (1420) (Neveux, 1996, p. 295-296). 
depuis longtemps, les chanoines regimbent désormais à accueillir ceux qui ont fait l'identité de leur maison! Les bourgeois précisent que les lépreux ne prennent aucune part à la gouvernance des biens du prieuré, seul apanage des chanoines ${ }^{178}$.

$\mathrm{Au}$ final, l'écrit n'est jamais efficace en soi $^{179}$ et la «magie» de l'écriture n'opère pas. Les cartulaires révèlent les mutations des communautés lépreuses et en ont été les garants. La rédaction des cartulaires de léproserie du $\mathrm{XV}^{\mathrm{e}}$ siècle est comparable à la lumière des supernovae: bien que l'astre fût déjà mort, son éclat parvenait encore aux yeux des contemporains ${ }^{180}$.

\section{Sources imprimées}

Basin, Thomas, Histoire de Charles VII, Charles Samaran (éd.), Paris, Les Belles Lettres («Les classiques de l'histoire de France au Moyen Âge»), 1933-1944, 2 vol.

Beaune, Colette (éd.), Journal d’un bourgeois de Paris de 1405 à 1449, Paris, Librairie Générale Française («Le Livre de Poche. Lettres gothiques»), nº 4522, 1990.

CAREL, Pierre (éd.), Étude sur la commune de Caen, suivie de la liste des échevins, analyse du matrologe de la ville et du cartulaire du cérémonial, Caen, A. Massif, 1888.

Deschamps, Eustache, «Ballade. Les temps des tourments approchent », in Auguste DE Queux de Saint-Hilaire et Gaston Raynaud (éd.), CEuvres complètes, I, Paris, Firmin Didot, 1878, n CLXII, p. 292 (1394).

ForevilLe, Raymonde (éd.), Latran I, II, III et Latran IV, Paris, Éditions de l'Orante («Histoire des conciles œcuméniques»), nº 6, 1965.

LÉCHAUDÉ D’ANISY, Amédée-Louis (éd.), «Rotuli Normanniæ ab anno MCCCCXVII ab annum MCCCCXII Henrico Quinto Angliæ rege», Mémoires de la Société des Antiquaires de Normandie, XV, 1846, p. 215-290.

Mesmin mac Dougall, Simone C. (éd.), The Leper Hospital of Saint-Gilles de PontAudemer: an edition of its cartulary and an examination of the problem of leprosy in the twelfth and early thirteenth century, Thèse de doctorat de philosophie, Reading, département d'Histoire, 1978. (dactyl.)

Puiseux, Léon (éd.), «Rôles normands et français et autres pièces tirées des archives de Londres par Bréquigny en 1764, 1765 et 1766\%, Mémoires de la Société des Antiquaires de Normandie, XXIII, 1858, p. 1-307.

Saint Augustin, La Cité de Dieu, Jean-Claude Escin (éd.), Paris, Les Éditions du Seuil («points sagesse»), no 75,76 et 77, 1994, 3 vol., 457 p., 369 p.

SAUVAge, René-Norbert, (éd.), «Les coutumes des métiers de Caen en 1326 », Mémoires de l'Académie nationale des Sciences et Belles-Lettres de Caen, 1914, p. 1-32.

178. «Et estoit vray que ledit priour de Saint-Nicolas estoit et est administratour dudit hostel, cuilloit, levoit le recevoit, cuilt levé et rechoit toutes les rentes et revenues d'icellui hostel tant ce qui estoit et appartenoit aus ladres dudit lieu, comme ce qui appartient au prioure et maladerie, sans ce que les diz ladres ne autres pour eulz s'en entremeissent en aucune maniere», cart. Saint-Nicolas, p. $41, \mathrm{n}^{\circ} 54$.

179. MORELLE, 1997, p. 298.

180. Le prieuré Saint-Nicolas s'éteint avec l'Ancien Régime. Le dernier chanoine, François Motet, meurt impotent à plus de 70 ans, le 11 juillet 1789. Caen, Arch. dép. Calvados, $1 \mathrm{Q} 9546$ vente des biens nationaux, Saint-Nicolas de la Chesnaie (1789-1792). 


\section{Bibliographie}

Arnoux, Mathieu et Maneuvrier, Christophe, «Deux abbayes de Basse-Normandie: Notre-Dame du Val et le Val Richer (XII ${ }^{\mathrm{e}}$-XIII ${ }^{\mathrm{e}}$ siècles)», Le Pays Bas-Normand, $\mathrm{n}^{\circ} 1-2, \mathrm{n}^{\circ} 237-238,2000$.

Baldwin, John W., Philippe Auguste et son gouvernement. Les fondations du pouvoir royal en France au Moyen Âge, Paris, Fayard, 1991.

BAldwin, John W., «Philip Augustus and the Norman Church», French Historical Studies, VI, 1969, p. 1-30.

Barthélemy, Dominique, La société dans le comté de Vendôme de l'an mil au XIV siècle, Paris, Fayard, 1993.

BAtes, David, «La "mutation documentaire" et le royaume anglo-normand (seconde moitié du XI ${ }^{\mathrm{e}}$ siècle-début du XII ${ }^{\mathrm{e}}$ siècle) ", in Les actes comme expression $d u$ pouvoir du Haut Moyen Âge, Actes de la table-ronde tenue à Nancy les 26 et 27 novembre 1999, Marie-José Gasse-Granjean et Benoît-Michel Tock (éd.), Turnhout, Brepols, 2003, p. 33-49.

BEAune, Colette, «Les structures politiques comparées de l'Occident médiéval (12501500)», in $X I V^{e}$ et $X V^{e}$ siècles: crises et genèse, Jean Favier (dir.), Paris, Presses Universitaires de France, 1996, p. 1-126.

Bertrand, Paul, «À propos de la révolution de l'écrit $\left(\mathrm{X}^{\mathrm{e}}-\mathrm{XIII}{ }^{\mathrm{e}}\right.$ siècle) considérations inactuelles», Médiévales, 56, 2009, p. 75-92.

Bors, Guy, Crise du féodalisme. Économie rurale et démographie en Normandie, $d u$ début du XIV ${ }^{e}$ siècle au milieu du XVI ${ }^{e}$ siècle, Paris, Éditions de l'École des hautes études en sciences sociales, $1976,2^{\mathrm{e}}$ éd., Paris, Presses de la fondation nationale des sciences politiques, 1981.

Bove, Boris, Le temps de la guerre de Cent Ans (1328-1453), Paris, Belin, 2010.

Briquet, Charles-Moïse, Les filigranes, dictionnaire historique des marques $d u$ papier dès leur apparition vers 1282 jusqu'en 1600, Genève, 1907, I, $2^{\mathrm{e}}$ éd. Leipzig, K. W. Hiersemann, 1923.

Brown, Peter, «Reliques et statut social au temps de Grégoire de Tours », in La société et le sacré dans l'Antiquité tardive, Peter Brown (éd.), Paris, Les Éditions du Seuil («Points Histoire»), n 316, 2002a, p. 185-214.

Brown, Peter, «La société et le surnaturel. Une transformation médiévale», in La société et le sacré dans l'Antiquité tardive, Peter Brown (éd.), Paris, Les Éditions du Seuil («Points Histoire»), $n^{\circ}$ 316, 2002b, p. 265-294.

Cabrol, dom Fernand et Leclerce, dom Henri (dir.), Dictionnaire d'archéologie chrétienne et de liturgie, I-2, Paris, Letouzey et Ané, 1924, 3274 col.

Carel, Pierre, Histoire de la ville de Caen depuis Philippe Auguste jusqu'à Charles IX (nombreux documents inédits), Paris, Honoré Champion, 1886.

Carruthers, Mary, Machina memorialis. Méditation, rhétorique et fabrication des images au Moyen Âge, Paris, Gallimard («Bibliothèque des Histoires»), 2002a.

Carruthers, Mary, Le livre de la mémoire: une étude de la mémoire dans la culture médiévale, Paris, Macula («Argôs»), 2002b.

Cassard, Jean-Christophe, L'âge d'or capétien 1180-1328, Paris, Belin, 2011. 
Chastang, Pierre, "Mémoire des moines et mémoire des chanoines. Réforme, production textuelle et référence au passé carolingien en Bas-Languedoc ( $\mathrm{XI}^{\mathrm{e}}$ $\mathrm{XII}^{\mathrm{e}}$ siècle)", in L'autorité du passé dans les sociétés médiévales, Jean-Marie SAnsterre (dir.), Rome, École française de Rome ("Collection de l'École française de Rome»), no 333, 2004, p. 177-202.

Chastang, Pierre, «Cartulaires, cartularisation et scripturalité médiévale: la structuration d'un nouveau champ de recherche», Cahiers de civilisation médiévale, nº 49, 2006, p. 21-32.

Chastang, Pierre, «L'archéologie du texte médiéval. Autour de travaux récents sur l'écrit au Moyen Âge», Annales. Histoire, Sciences Sociales, no 2, 2008, p. 245-269.

Chastang, Pierre, «Introduction», Tabularia «Études», nº 9, 2009, p. 27-42.

Chaunu, Pierre, "L'État», in Histoire économique et sociale de la France I. 1450-166o. L'État et la ville. Paysannerie et croissance, Fernand Braudel et Ernest Labrousse (dir.), Paris, Presses Universitaires de France («Quadrige»), nº 161, $2^{\mathrm{e}}$ éd., 1993, p. 11-228.

Clanchy, Michael T., England and its rulers (1066-1272): foreign lordship and national identity, Glasgow, Fontana Paperbacks, 1983.

Coville, Alfred, Les États de Normandie, leurs origines et leur développement au $X I V^{e}$ siècle, Paris, Imprimerie nationale, 1894.

Dalarun, Jacques, Gouverner c'est servir. Essai de démocratie médiévale, Paris, Alma éditeur, 2012.

DÉDouit, Alfred, Bayeux sous la Révolution, le Consulat et l'Empire. Souvenirs inédits, Bellême, Georges Levayer, 1892.

Denifle, Henri (éd.), La désolation des églises, monastères, hôpitaux en France vers le milieu du XV $V^{e}$ siècle, Paris, Picard, 1897 et 1899, 2 vol.

Derrida, Jacques, «La pharmacie de Platon», in La dissémination, Jacques DerridA (éd.), Paris, Éditions du Seuil («Points Essais»), nº 265, $2^{\mathrm{e}}$ éd., 1972, p. 77-213.

DoucET, Roger, «Les finances anglaises à la fin de la guerre de Cent ans (1413-1435)», Le Moyen Âge, 36, 1926, p. 265-332.

Delisle, Léopold, «La léproserie de Bolleville», Annuaire du département de la Manche, 1892, p. 16-27.

Galeron, Frédéric (dir.), Statistique de l'arrondissement de Falaise, I, Falaise, Brée l'aîné, 1826.

Garnier, Charles, «Les hospices de Bayeux, notes historiques», Mémoires de la Société des sciences, arts et belles-lettres de Bayeux, X, 1908, p. 1-137.

Gauvard, Claude, "De grace especial». Crime, État et société en France à la fin $d u$ Moyen Âge, Paris, Publications de la Sorbonne, 1991, $2^{\mathrm{e}}$ éd., coll. "Les classiques de la Sorbonne», $\mathrm{n}^{\circ}$ 1, 2010.

GeAry, Patrick, "Auctor et auctoritas dans les cartulaires du haut Moyen Âge», in Auctor et auctoritas. Invention et conformisme dans l'écriture médiévale, Michel Zimmermann (dir.), Paris, École des chartes («Mémoires et documents de l'École des chartes»), n 59, 2001, p. 61-71.

Girard, René, La Violence et le Sacré, Paris, Grasset, 1972, $7^{\mathrm{e}}$ éd., Paris, Hachette («Pluriel Philosophie»), 2006. 
Guerreau-Jalabert, Anita, «Parole/parabole. La parole dans les langues romanes: analyse d'un champ lexical et sémantique», in La parole du prédicateur ( $V^{e}$ $X V^{e}$ siècle), Rosa Maria Dessì et Michel Lauwers (dir.), Nice, Centre d’Études Médiévales, 1997, p. 313-320.

Guyotjeannin, Olivier, Picke, Jacques et Tock, Benoît-Michel, Diplomatique médiévale, Turnhout, Brepols («Collection du Centre d’Études Médiévales de Nice»), $\mathrm{n}^{\circ} 1,1993$.

Guyotjeannin, Olivier, "Antiqua et authentica praedecessorum nostrorum nos ammonent. Appel et rejet du passé chez les rédacteurs d'actes occidentaux (VIII ${ }^{\mathrm{e}}$ $\mathrm{XIV}^{\mathrm{e}}$ siècle) », in L'autorité du passé dans les sociétés médiévales, Jean-Marie SANSTERRE (dir.), Rome, École française de Rome (« collection de l'École française de Rome»), n³ 333, 2004, p. 9-25.

HeNRIET, Patrick, «Res gestas scripti memorie comendare. Rufat et le premier cartulaire de Saint-Seurin (années 1160-119o)», in Autour de Saint-Seurin: lieu, mémoire, pouvoir des premiers chrétiens à la fin du Moyen Âge, Isabelle CARTron, Dany Barraud, Patrick Henriet et Anne Michel, Bordeaux, Ausonius, 2009, p. 129-140.

Houth, Émile, "Les Comtes de Meulan», Mémoires de la Société historique et archéologique de Pontoise, du Val d'Oise et du Vexin, LXX, 1981.

JEAnne, Damien, Garder ou perdre la face? La Maladie et le Sacré. Étude d'anthropologie historique sur la lèpre (Normandie centrale, occidentale et méridionale) du XI au $X V I^{e}$ siècle, thèse de doctorat d'histoire, Colette Beaune (dir.), Paris-Ouest-Nanterrela-Défense, UFR d'Histoire, 2010a, 4 vol. (dactyl.).

JEAnne, Damien, «Le roi charitable. Les politiques royales envers les établissements d'assistance de la Normandie centrale et occidentale, XIII ${ }^{\mathrm{e}}-\mathrm{XV}^{\mathrm{e}}$ siècle», in Une histoire pour un royaume (XII ${ }^{e}-X V^{e}$ siècle), Actes du colloque Corpus Regni organisé en hommage à Colette Beaune, Anne-Hélène Allirot, Murielle Gaude-Ferragu, Gilles Lecuppre, Élodie Lequain, Lydwine Scordia et Julien Véronèse (éd.), Paris, Perrin, 2010b, p. 102-123.

Jouet, Roger, La résistance à l'occupation anglaise en Basse-Normandie (1418-1450), Cahiers des Annales de Normandie, 5, Caen, 1969.

Jouet, Roger, «La ville “anglaise” et la réadaptation au royaume», in Histoire de Caen, Gabriel DÉSERT (dir.), Toulouse, Privat, 1981, p. 93-113.

Jouet, Roger, «La tourmente» in Histoire de la Normandie, Michel de BoüARD (dir.), Toulouse, Privat, 1970, $2^{\mathrm{e}}$ éd. 1984, p. 219-253.

Langevin, Pierre-Gilles, Recherches historiques sur Falaise, Falaise, Brée l'aîné, 1814.

Le BlÉvec, Daniel, La part du pauvre. L'assistance dans les pays du Bas-Rhône du $X I I^{e}$ au milieu $d u X V^{e}$ siècle, Rome, École Française de Rome, 2000, 2 vol.

Le Prévost, Auguste, Mémoires et notes pour servir à l'histoire du département de l'Eure, Évreux, A. Hérissey, 1862-1869, 3 vol.

Lusignan, Serge, La langue des rois au Moyen Âge. Le français en France et en Angleterre, Paris, Presses Universitaires de France, 2004.

Mesmin mac Dougall, Simone C., «Waleran, count of Meulan and the Leper Hospital of S. Gilles de Pont-Audemer», Annales de Normandie, 1, 1982, p. 4-19.

Mesmin mac Dougall, Simone C., «Du comte à la commune: la léproserie de PontAudemer», Annales de Normandie, 3, 1987, p. 235-267. 
Miramon, Charles (de), Les «donnés » au Moyen Âge. Une forme de vie religieuse lä̈que (v. 1180-v. 1500), Paris, Les Éditions du Cerf, 1999.

Mollat, Guillaume, "Le droit de patronage en Normandie du XI ${ }^{e}$ au XVe siècle», Revue d'histoire ecclésiastique, XXXIII, 3, 1937, p. 478-48o.

Mollat, Michel, Le commerce maritime normand à la fin du Moyen Âge. Étude d'histoire économique et sociale, Paris, Plon, 1952.

MoRELLE, Laurent, «De l'original à la copie: remarques sur l'évaluation des transcriptions dans les cartulaires médiévaux» in Les cartulaires, Actes de la Table ronde organisée par l'École nationale des chartes, 1991, Olivier Guyotjeannin, Laurent Morelle et Michel Parisse (éd.), Paris, École des chartes («Mémoires et documents de l'École des chartes»), $\mathrm{n}^{\circ} 39,1993$, p. 91-102.

Morelle, Laurent, «Les chartes dans la gestion des conflits (France du Nord, $\mathrm{XI}^{\mathrm{e}}$-début XII e siècle) ", in Pratiques de l'écrit documentaire au XI' siècle, Olivier Guyotjeannin, Laurent Morelle et Michel Parisse (éd.), Bibliothèque de l'École des chartes, 155, 1997, p. 267-298.

Morelle, Laurent, «La mise en "œuvre” des actes diplomatiques. L'auctoritas des chartes chez quelques historiographes monastiques (IX ${ }^{\mathrm{e}}-\mathrm{XI}{ }^{\mathrm{e}}$ siècle)", in Auctor et auctoritas. Invention et conformisme dans l'écriture médiévale, Michel ZimmermanN (dir.), Paris, École des chartes («Mémoires et documents de l'École des chartes»), $\mathrm{n}^{\circ}$ 59, 2001, p. 73-96.

MoRELLE, Laurent, «Instrumentation et travail de l'acte: quelques réflexions sur l'écrit diplomatique en milieu monastique au $\mathrm{XI}^{\mathrm{e}}$ siècle», Médiévales, 56, 2009, p. 41-74.

Morsel, Joseph, «Le cartulaire de Sigmund I von Thüngen (Franconie, 1448/49)», in Les cartulaires, Actes de la table ronde organisée par l'École nationale des chartes, 1991, Olivier Guyotjeannin, Laurent Morelle et Michel Parisse (éd.), Paris, École des chartes («Mémoires et documents de l'École des chartes»), nº 39, 1993, p. 409-422.

Morsel, Joseph, "Ce qu'écrire veut dire au Moyen Âge. Observations préliminaires à une étude de la scripturalité médiévale", Memini. Travaux et documents de la Société des études médiévales du Québec, no 4, 2000, p. 3-43.

Musset, Lucien, «Les apports anglais en Normandie de Rollon à Guillaume le Conquérant (911-1066)», in Nordica et Normannica. Recueil d'études sur la Scandinavie ancienne et médiévale, les expéditions des Vikings et la fondation de la Normandie, Lucien Musset, Paris, Société des Études Normandes, 1997, p. 447-466.

Navel, Henri, «Vindinc et houellant», Bulletin de la Société des Antiquaires de Normandie, XLIV, 1937, p. 435.

Neveux, François, Bayeux et Lisieux. Villes épiscopales normandes, Caen, Éditions du Lys, 1996.

Neveux, François, La Normandie pendant la guerre de Cent Ans (XIV ${ }^{e}-X V^{e}$ siècle), Rennes, Éditions Ouest-France, 2008.

Newhall, Richard Ager, «Henry V's policy of conciliation in Normandy, 1418-1422», in Anniversary essays in mediaeval History by students of Charles Homer Haskins, Boston-New York, Hougthon Mifflin Cie, 1929, p. 205-230. 
Offenstadt, Nicolas, «Le rite et l'histoire. Remarques introductives», Hypothèses, 1, 1997, p. 7-14.

RideL, Élisabeth, Les vikings et les mots. L'apport de l'ancien scandinave à la langue française, Paris, Éditions Errance, 2009.

Robillard de Beaurepaire, Charles (de), «Les États de Normandie sous la domination anglaise ", Recueil des travaux de la Société libre d'agriculture, sciences, arts et belleslettres de l'Eure, V, 1857-1858, 1859, p. 347-541.

Scordia, Lydwine, Le roi doit vivre du sien. La théorie de l'impôt en France (XIII ${ }^{e}-$ $X V^{e}$ siècles), Paris, Institut d'études augustiniennes, 2004.

TAButeau, Bruno, Une léproserie normande au Moyen Âge. Le prieuré de Saint-Nicolas d'Évreux du XII e au XVI siècle. Histoire et corpus des sources, Thèse de Doctorat d'Histoire nouveau régime, Rouen, UFR d'Histoire, J.-P. Leguay (dir.), 1996, (dactyl.), 3 vol.

ThÉвAult, Marion, «Le "premier cartulaire" de l'abbaye de Mondaye», Annales de Normandie, 1, 2011, p. 25-47.

Touati, Francois-Olivier, "Cartulaires de léproserie dans la France du Nord (XIII ${ }^{\text {- }}$ $\mathrm{XV}^{\mathrm{e}}$ siècle)", in Les cartulaires, Actes de la table ronde organisée par l'École nationale des chartes, 1991, Olivier Guyotjeannin, Laurent Morelle et Michel Parisse (éd.), Paris, École des chartes («Mémoires et documents de l'École des chartes"), $\mathrm{n}^{\circ} 39,1993$, p. 467-501.

Touati, François-Olivier, Maladie et société au Moyen Âge. La lèpre, les lépreux et les léproseries dans la province ecclésiastique de Sens, jusqu'au milieu du XIVe siècle, Paris, Bruxelles, De Boeck Université, 1998.

Vauchez, André, La spiritualité du Moyen Âge occidental, VIII - -XIII ${ }^{e}$ siècles, Paris, Les Éditions du Seuil («Points Histoire»), n $184,1994$.

Yver, Jean, Les contrats dans le très ancien droit normand (XI ${ }^{e}$-XIII ${ }^{e}$ siècles), Domfront, Imprimerie F. Marsat, 1926.

Zimmermann, Michel, «Sicut antiquitus sancitum est... Tutelle des anciens ou protection de l'innovation? L'invocation du droit et la terminologie politique dans les représentations médiévales en Catalogne ( $\mathrm{IX}^{\mathrm{e}}-\mathrm{XII}{ }^{\mathrm{e}}$ siècle) », in L'autorité du passé dans les sociétés médiévales, Jean-Marie SANsterre (dir.), Rome, École française de Rome («Collection de l'École française de Rome»), n 333, 2004, p. 27-56. 


\section{Figures}

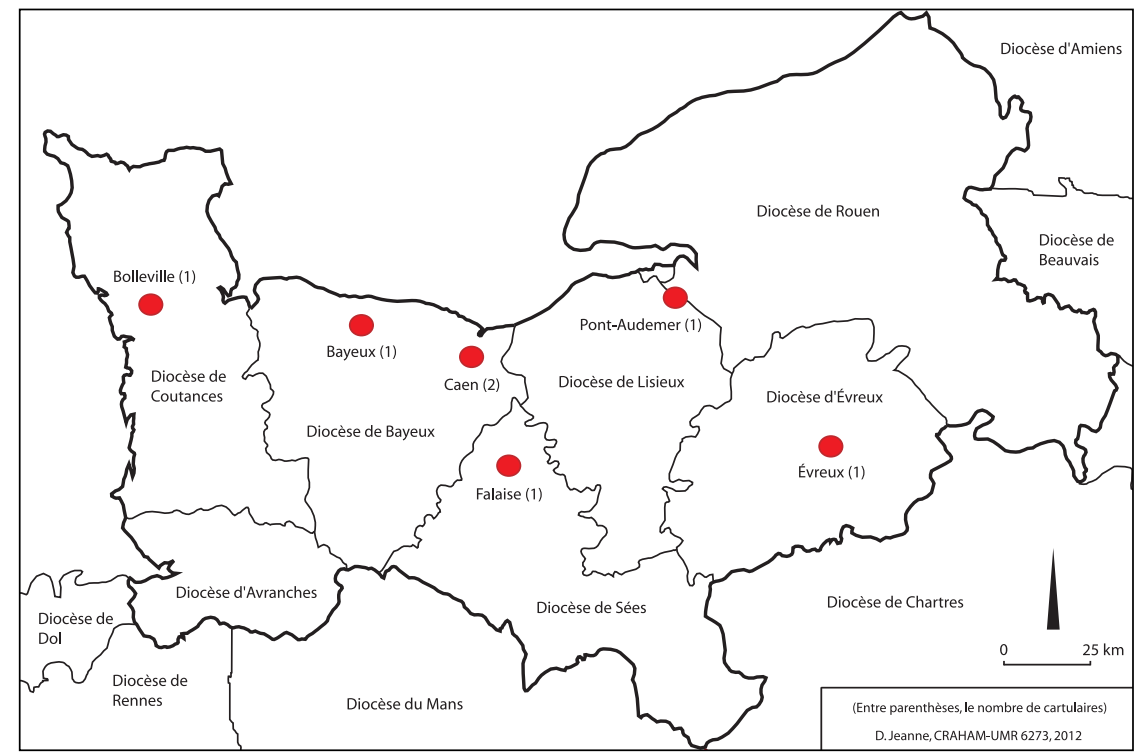

Figure 1: répartition des cartulaires de léproseries dans la province ecclésiastique de Rouen.
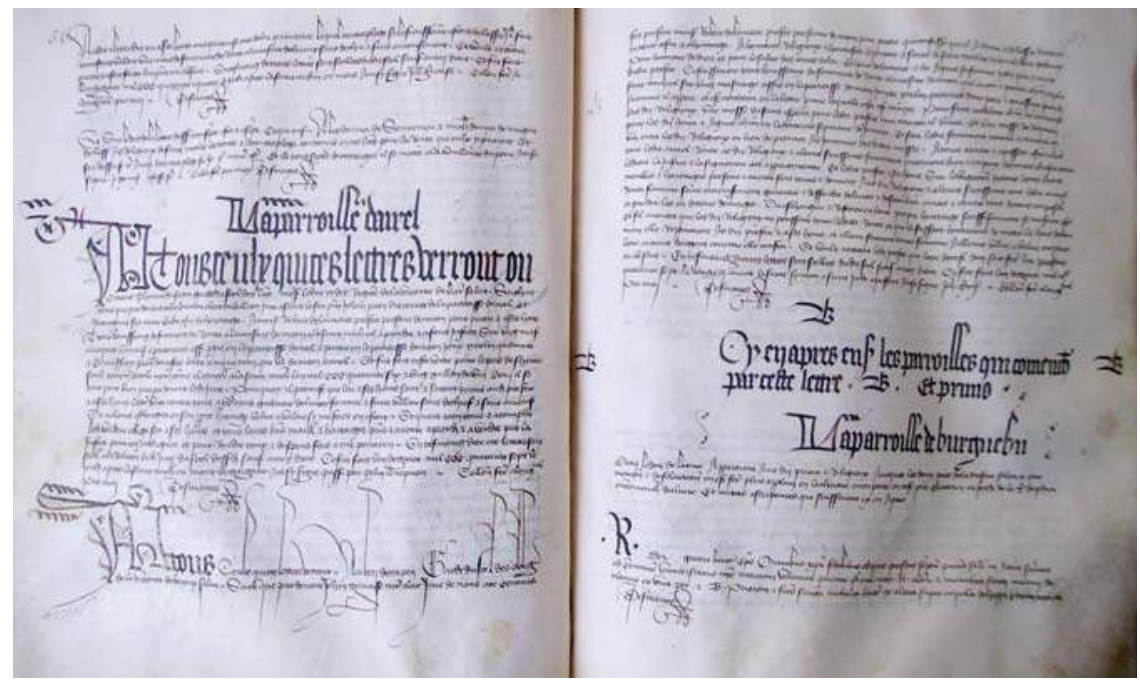

Figure 2: cartulaire de Saint-Nicolas de Bayeux, p. 56-57 (1438), Bayeux, Bibl. mun., ms 1 (cl. D. Jeanne). 


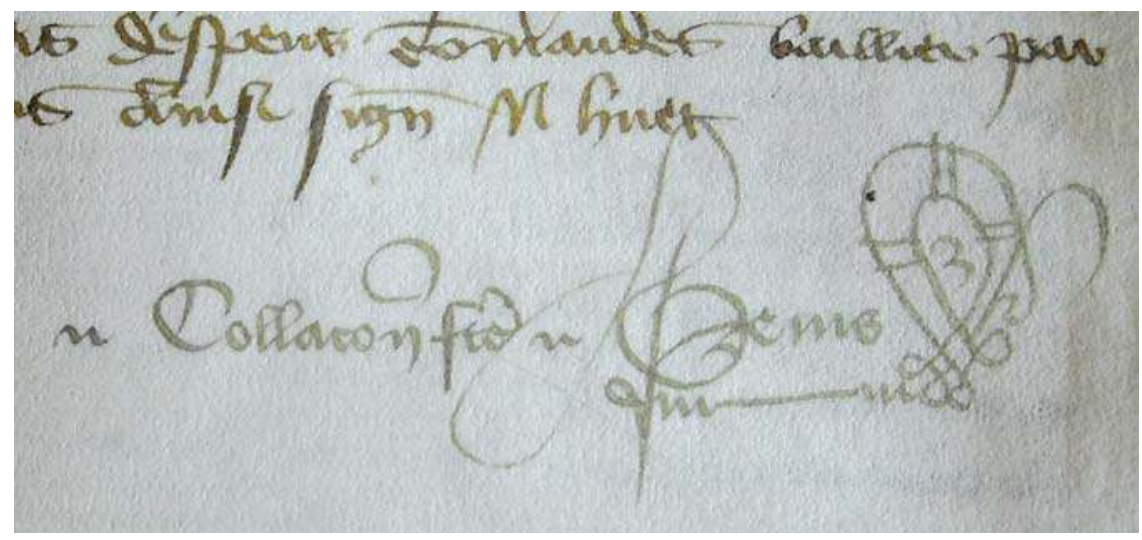

Figure 3: signature de Guillaume Denis - Cartulaire de N.-D. de Beaulieu de Caen, 1433, Caen, Arch. dép. Calvados, H suppl. 5034, fol. 7v (cl. D. Jeanne).

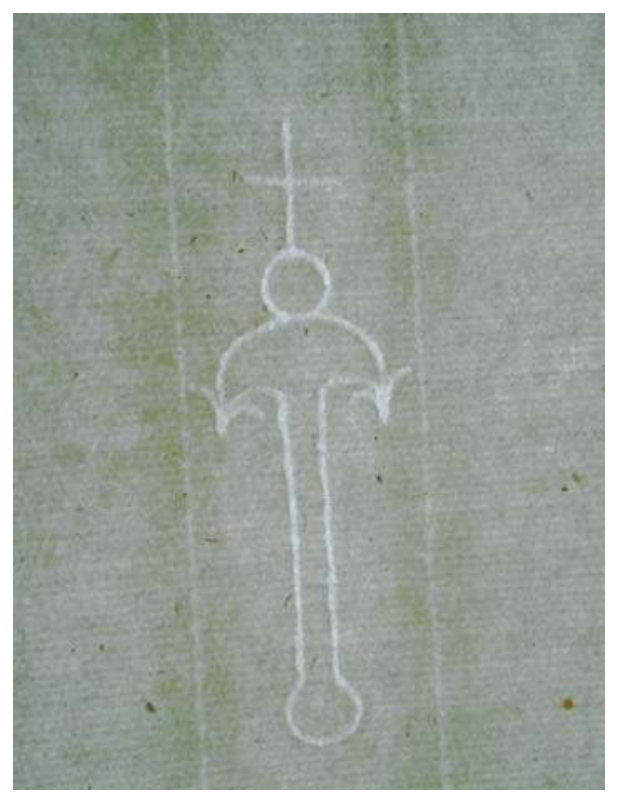

Figure 4: filigrane en forme d'ancre surmontée d'un globe terrestre et d'un crucifix sur papier Lombard. Cartulaire de Saint-Lazare de Falaise, fol. 106v (80 x 230 mm - 1487), Caen, Arch. dép. Calvados, 386 Edt 635 (cl. D. Jeanne). 


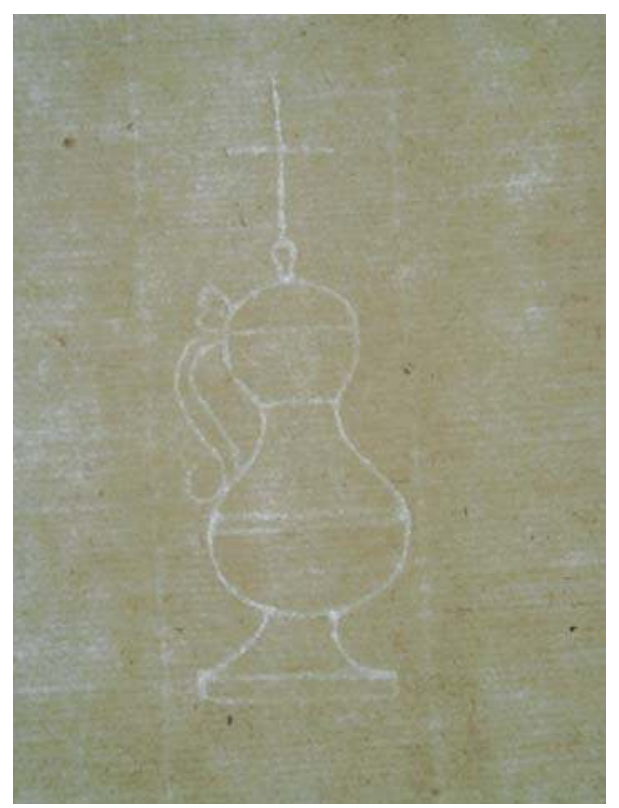

Figure 5: filigrane représentant un pot d'étain avec couvercle et anse surmonté d'une croix sur papier Lombard. Cartulaire de Saint-Lazare de Falaise, fol. 237v (77 x 25 mm - 1487), Caen, Arch. dép. Calvados, 386 Edt 635 (cl. D. Jeanne).

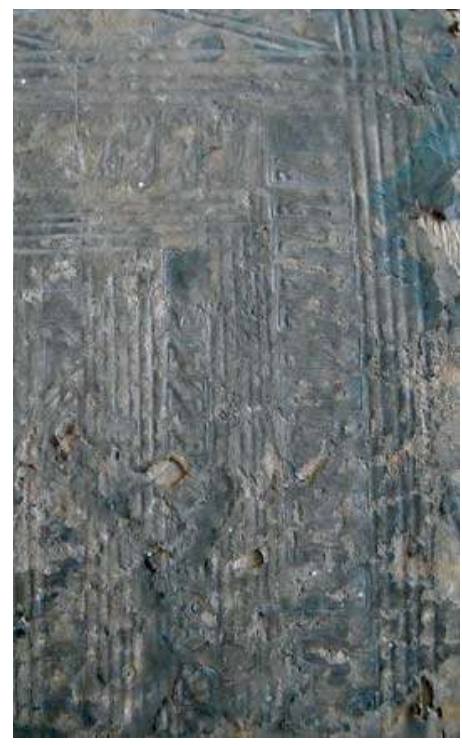

Figure 6: léopards estampés sur cuir - Couverture du cartulaire de N.-D. de Beaulieu de Caen, v. 1460?, Caen, Arch. dép. Calvados, Hnc 292 (cl. D. Jeanne).

http://www.unicaen.fr/mrsh/craham/revue/tabularia/print.php?dossier=dossier9\&file=06jeanne.xml 